Boletín Epidemiológico Semanal

Las infecciones respiratorias agudas (IRA) son consideradas una de las principales causas de morbilidad y mortalidad en el mundo, y los menores de cinco años son el grupo poblacional con mayor riesgo de morir por esta causa. En Colombia la IRA es la quinta causa de mortalidad en población general y se ubica entre las tres primeras causas en menores de cinco años.

Históricamente el comportamiento de la IRA en Colombia presenta dos incrementos de consultas y hospitalizaciones por esta enfermedad; el primer incremento se observa entre marzo a junio, mayo y junio los que concentran el mayor número de casos. El segundo incremento se presenta entre septiembre a diciembre, con un número de casos menor comparado con lo registrado durante el primer semestre del año.

A semana epidemiológica 40 de 2019 se han registrado 5196943 consultas externas y urgencias por IRA presentando una disminución del 5,2 \% con respecto al 2018, en cuanto a las hospitalizaciones por IRA en sala general se han notificado 177181 registros con una disminución del 8,8 \% con respecto a la notificación de 2018; en las hospitalizaciones por IRA en unidad de cuidados intensivos (UCI) se han notificado 16524 registros con una disminución del 6,7\% frente a la misma semana de 2018 (Tabla 1).

Tabla 1. Notificación morbilidad por infección respiratoria aguda por tipo de servicio en Colombia, semanas epidemiológicas 01 a 40, 2019

\begin{tabular}{lrrrr} 
Tipo de servicio & 2018 a semana 40 & 2019 a semana 40 & Variación \\
\hline Consultas ambulatorias y urgencias & 5483657 & 5196943 & $5,2 \%$ & Disminución \\
Hospitalizaciones en sala general & 194322 & 177181 & $8,8 \%$ & Disminución \\
Hospitalizaciones en UCl & 17716 & 16524 & $6,7 \%$ & Disminución \\
\multicolumn{1}{c}{ Fuente: Sivigila, Instituto Nacional de Salud, Colombia, 2018 a 2019 } & &
\end{tabular}

En el servicio de consultas externas y urgencias a semana 40 de 2019, se identificó un incremento en el grupo de 5 a 19 años que supera el límite histórico; en las hospitalizaciónes en sala general los adultos de 60 años y mas presentan un incremento sin superar el limite establecido. En el servicio de hopitalización en $\mathrm{UCl}$ todos los grupos de edad presentan incrementos; sin embargo, solo las personas de 2 a 4 años y 60 y más años, superan el límite histórico (Figura 1).
Figura 1. Comportamiento de la infección respiratoria aguda por grupos de edad, Colombia, 2013 a semana epidemiológica 40 de 2019

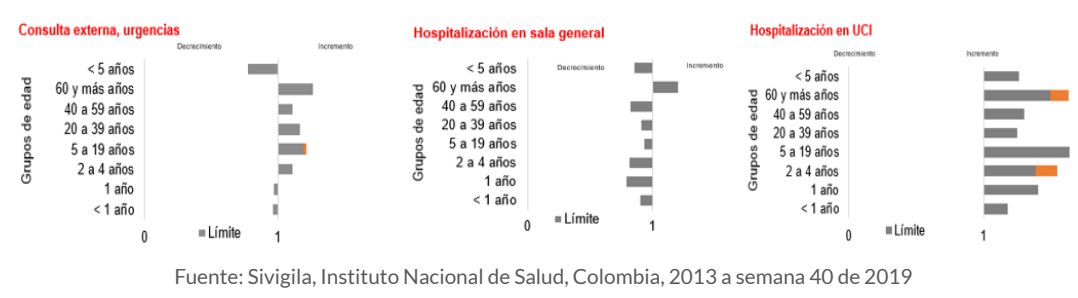

Arauca, Bogotá, Tolima, Buenaventura y Vichada presentan incrementos estadistiamente significativos en la notificacion de consultas externas y urgencias por IRA y Vaupés y Amazonas presentan disminuciones significativas. En las hospitalizaciones en salageneral se presentan incrementos significativos en Magdalena, Tolima, Casanare, Vichada y Bolívar. En el servicio de hospitalización en (UCI) las entidades territoriales de Cesar, Sucre, Norte de Santander, Santander y Bogotá presentan incrementos; La Guajira, Santa Marta, Córdoba, Valle del Cauca, Cauca, Nariño y Caquetá reportan una disminucion en la notificacion para estas ultimas 4 semanas de 2019 (Mapa 1).

Mapa 1. Comportamientos inusuales de la infección respiratoria aguda por entidades territoriales, Colombia, 2013 a semana epidemiológica 40 de 2019
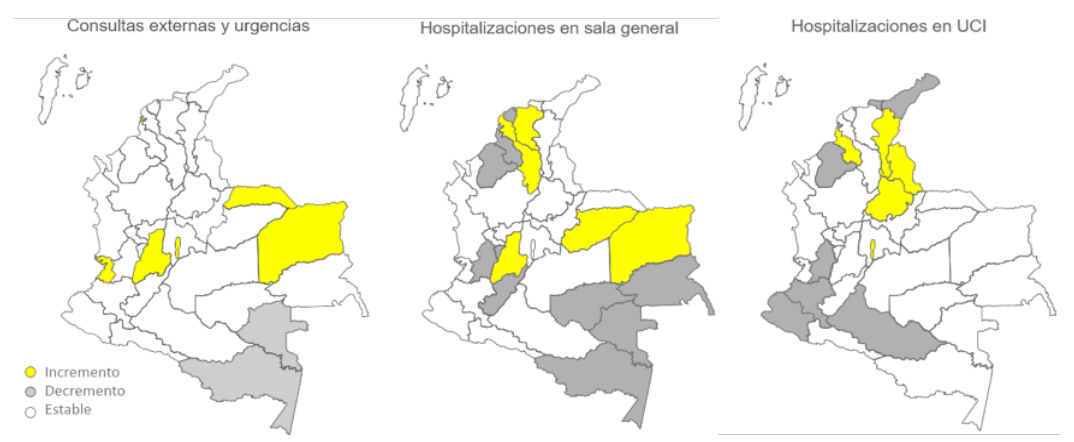

Fuente: Sivigila, Instituto Nacional de Salud, Colombia, 2019

Con respecto a las muertes por IRA notificadas, en Colombia a la fecha se cuenta con 660 muertes, de las cuales el 70 \% (462) corresponde a menores de cinco años; en comparación con el mismo periodo del 2018, se presenta una disminución del $21,1 \%$. El canal endémico a permanecido por debajo del limite superior histórico durante las últimas 4 semanas (Figura 2).
Tema central

Situación Nal.

Mortalidad

Trazadores

Brotes

Sarampión

Tablas
INSTITUTO NACIONA 
Figura 2. Canal endémico de muertes por infección respiratoria aguda, Colombia, semanas epidemiológicas 01 a 40, entre 2013 y 2019

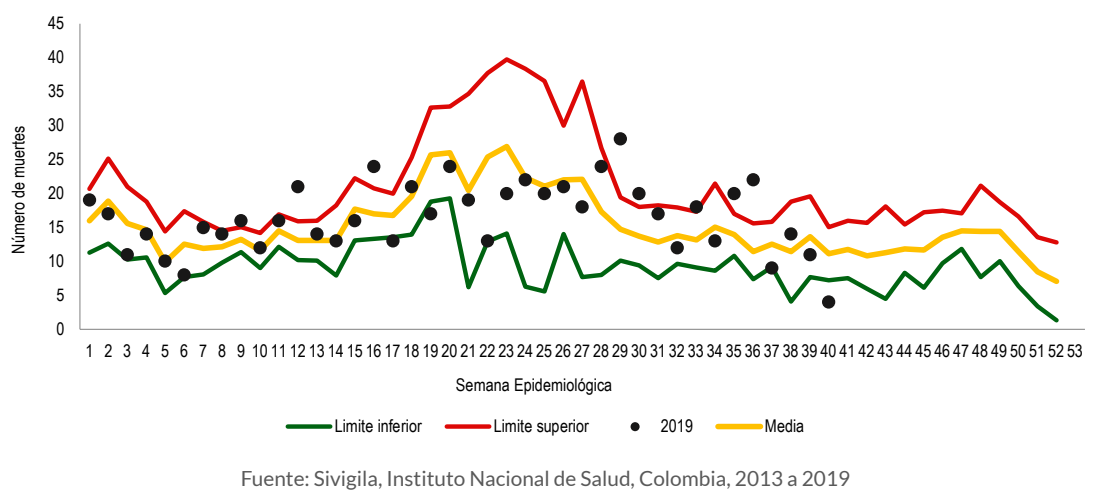

La tasa ajustada de mortalidad por IRA para el 2019 ha disminuido principalmente en las entidades territoriales de Tolima, Cauca, Cundinamarca, Huila, Sucre, Santander, Atlántico, Putumayo, Córdoba, Boyacá y Nariño en comparación con 2018 (Mapa 2).

Mapa 2. Tasa ajustada de muertes por IRA en Colombia, semanas epidemiológicas 01 a 40, 2018 - 2019

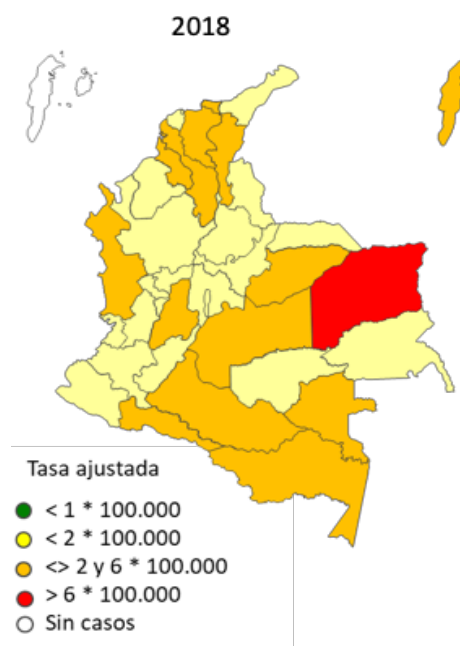

2019

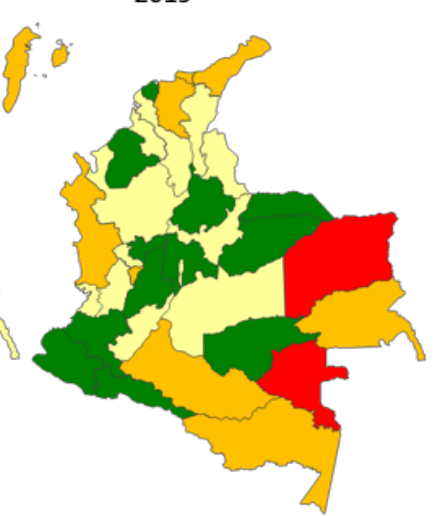

\section{Conclusiones y recomendaciones}

- La actividad de influenza en Colombia suele estar presente durante todo el año, por lo tanto los médicos deben considerar la influenza en el diagnóstico diferencial de enfermedades respiratorias en cualquier momento del año.

- Si bien la influenza A(H1N1)pdm09 tiende a dar connotaciones de gravedad a nivel nacional por su antecedente pandémico, este virus es uno más de los agentes que puede ocasionar aumento de casos en la población, por lo que es importante tener presente otros agentes como VSR.

- Se deben fortalecer las estrategias de vacunación dirigidas a la comunidad en general y al personal de sector salud, con el fin de alcanzar coberturas útiles de vacunación, especialmente en la población objeto, como lo establece el lineamiento nacional para la vacunación contra influenza estacional emitido por el Programa Ampliado de Inmunizaciones del Ministerio de Salud y Protección Social.

- Es necesario fortalecer en el personal de salud, conocimientos frente a los protocolos y guías vigentes para la vigilancia y atención de la IRA, así como las Guías de Práctica Clínica y lineamientos relacionados con enfermedad respiratoria aguda, neumonía, bronquiolitis, tosferina, influenza entre otras, a fin de garantizar el cumplimiento de los indicadores del evento en especial los relacionados con recolección de muestras respiratorias.

- En vista del segundo pico respiratorio las IPS, secretarías de salud y demás instituciones del sector deben activar sus planes de contingencia y fortalecer las estrategias de identificación, notificación, diagnóstico, tratamiento, prevención con vacunación y comunicación del riesgo para el público en general 


\section{SITUACIÓN NACIONAL}

\section{Tablero de control del análisis de datos de la vigilancia}

Para el análisis de los eventos de mayor notificación en el país, se compara el valor observado en la semana epidemiológica correspondiente, con una línea de base de referencia, que está conformada con la información de esos eventos reportados en 15 intervalos de tiempo de al menos cinco años anteriores.

Se identifica que en semana epidemiológica 40 , los eventos de sífilis gestacional y dengue se encuentran por encima de sus valores esperados, mientras que leishmaniasis cutánea, intoxicaciones, agresiones por animales transmisores de rabia y varicela, están por debajo de los valores esperados. Los demás eventos están dentro del comportamiento histórico de la notificación (Figura 3).

Figura 3.Comparación de la notificación de casos de eventos priorizados, según su comportamiento histórico. Colombia, Semana epidemiológica 40 de 2019

$$
\begin{array}{r}
\text { MME } \\
\text { Malaria } \\
\text { Sífilis gestacional } \\
\text { Tos ferina } \\
\text { Dengue grave } \\
\text { Accidente ofídico } \\
\text { Parotiditis } \\
\text { rinatal y neonatal tardía } \\
\text { Leishmaniasis cutánea } \\
\text { Bajo peso al nacer } \\
\text { Intoxicaciones } \\
\text { Dengue } \\
\text { Agresiones por APTR } \\
\text { Varicela individual }
\end{array}
$$

Mortalidad perinatal y neonatal tardía

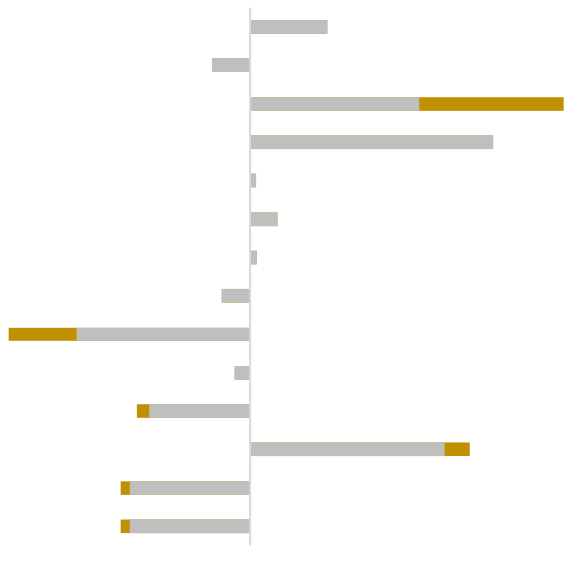

\section{0,0}

$$
\square \text { Esperado } \quad \square \text { Inesperado }
$$

Fuente: Sivigila, Instituto Nacional de Salud, Colombia, 2019

Para el análisis de los eventos de baja frecuencia o raros, se comparan los casos observados y los esperados según su comportamiento histórico. Se calcula la probabilidad de la significación estadística de la comparación. Valores menores a 0,05 en la columna "Poisson" indican que existe una diferencia significativa entre lo observado y lo esperado para la semana analizada.

Los casos notificados de sarampión superan lo esperado. La notificación de ESAVI, leptospirosis, sífilis congénita, e IRAG inusitado, presentan diferencias estadísticas. Los demás eventos se encuentran dentro del comportamiento histórico establecido (Tabla 2).

Tabla 2. . Comparación de casos notificados de eventos priorizados, según su comportamiento histórico, Colombia, semana epidemiológica 40 de 2019

$\begin{array}{lrrr}\text { Evento } & \text { Observado } & \text { Esperado } & \text { Poisson } \\ \text { ESAVI } & 10 & 209 & 0,00 \\ \text { Sarampión } & 40 & 61 & 0,00 \\ \text { Leptospirosis } & 20 & 36 & 0,00 \\ \text { Síflis congénita } & 27 & 22 & 0,00 \\ \text { IRAG inusitado } & 19 & 29 & 0,01 \\ \text { Rubeola } & 5 & 17 & 0,09 \\ \text { Mortalidad por IRA } & 9 & 8 & 0,12 \\ \text { Lepra } & 3 & 8 & 0,14 \\ \text { Tuberculosis fármacorresistente } & 1 & 7 & 0,15 \\ \text { Mortalidad materna } & 7 & 7 & 0,15 \\ \text { Fiebre tifoidea y paratifoidea } & 0 & 4 & 0,16 \\ \text { Mortalidad por dengue } & 5 & 2 & 0,18 \\ \text { Mortalidad por EDA 0-4 Años } & 2 & 2 & 0,21 \\ \text { Leishmaniasis mucosa } & 0 & 2 & 0,30\end{array}$

\section{Cumplimiento en la notificación}

El $100 \%$ de las unidades notificadoras departamentales y distritales (UND) cumplió con el reporte, igual que la semana anterior del presente año y aumento $2,7 \%$ respecto a la misma semana del 2018. El país cumplió con la meta establecida del 100 \% en la notificación de UND.

\begin{tabular}{l} 
Tema central \\
\hline Situación Nal. \\
Mortalidad \\
\hline Trazadores \\
\hline Brotes \\
Sarampión \\
Tablas
\end{tabular}


El reporte de las unidades notificadoras municipales (UNM) a nivel nacional fue $100 \%$ (1 117 / 1117 UNM), permaneció igual respecto a la semana anterior, y aumento $2,6 \%$, relacionado con la misma semana del año 2018. El país cumplió con la meta del $97 \%$ en la notificación de UNM.

El cumplimiento de las Unidades Primarias Generadoras de Datos UPGD) en esta semana fue de 98,38 \% (5 161/ 5246 UPGD); aumento $0,2 \%$, respecto a la semana anterior y $1,72 \%$ frente a la misma semana de 2018. El país cumplió con la meta del $90 \%$ en la notificación de UPGD (Figura 4)

Figura 4. Cumplimiento de la notificación por UPGD, Colombia, semanas epidemiológicas 01 a 402019

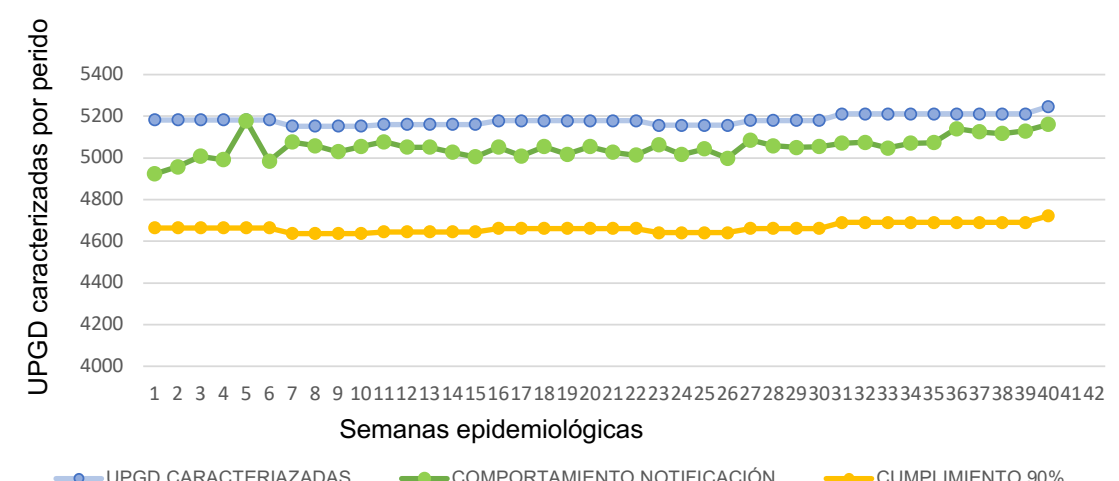

Fuente: Sivigila, Instituto Nacional de Salud, Colombia, 2019

\section{MORTALIDAD}

Mortalidad en menores de 5 años por eventos priorizados, semana epidemiológica 40 de 2019

Esta semana se notificaron 16 muertes en menores de 5 años: 9 probablemente asociadas a infección respiratoria aguda, 2 a enfermedad diarreica aguda y 5 a desnutrición.

\section{Mortalidad por infección respiratoria aguda}

Se notificaron 9 casos de muerte por infección respiratoria aguda en menores de 5 años. Para la misma semana de 2018 se notificaron 7 casos.

Respecto a las muertes acumuladas a semana epidemiológica 40 se observó una disminución en el número de casos en comparación con el histórico notificado en el mismo periodo 2014 a 2018 en los departamentos de Antioquia, Bogotá, Cundinamarca, Sucre y Tolima, mientras que, en Magdalena, Santander, Valle del Cauca y Vaupés se observó un aumento. En las entidades territoriales restantes no se presentaron variaciones (figura 5).

Figura 5 Entidades Territoriales con variaciones significativas respecto al promedio de casos notificados por mortalidad por infección respiratoria aguda, 2014 a 2018, Colombia, semana epidemiológica 40 de 2019*

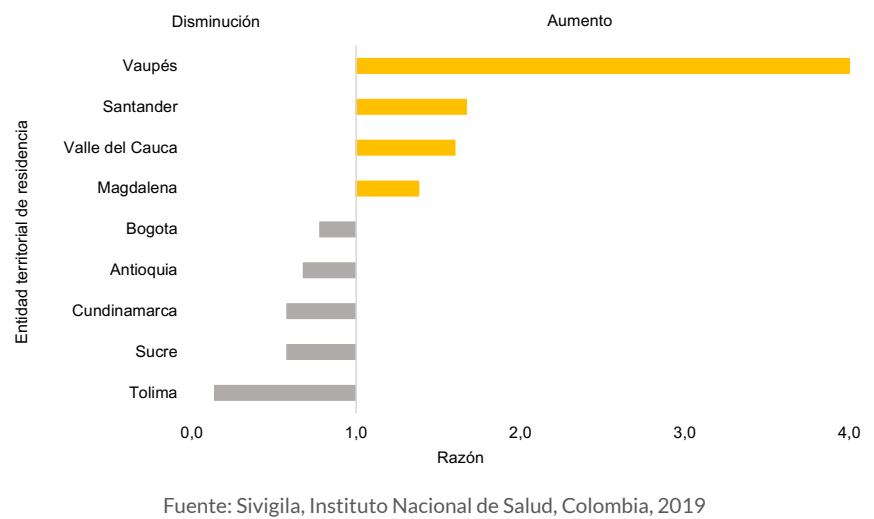

Tema central

Situación Nal.

Mortalidad

Trazadores

Brotes

Sarampión

Tablas 


\section{Mortalidad por enfermedad diarreica aguda}

Para esta semana se notificaron 2 casos de muerte por enfermedad diarreica aguda en menores de 5 años, 1 de esta semana y 1 de semanas anteriores. Para la misma semana de 2018 no se notificaron casos.

Respecto a las muertes acumuladas a semana epidemiológica 40 se observó un aumento en el número de casos en comparación con el histórico notificado en el mismo periodo 2013 a 2018 en los departamentos de Norte de Santander, La Guajira y Chocó. En las entidades territoriales restantes no se observaron variaciones.

\section{Mortalidad por desnutrición}

Se notificaron 5 casos probables de muerte por y asociada a desnutrición en menores de 5 años, 2 de esta semana y 3 de semanas anteriores. Para la misma semana de 2018 se notificaron 2 casos.

Asemana epidemiológica 40, seobservóuna disminuciónenel número de casos en comparación con el histórico notificado en el mismo periodo 2014 a 2018 en los departamentos Córdoba, Guaviare y La Guajira, mientras que, en los departamentos de Barranquilla, Norte de Santander y Vichada se observó un aumento. En las entidades territoriales restantes no se observaron variaciones.

*Para el análisis de los datos se tomó el comportamiento de cada uno de los eventos a semana epidemiológica 40 entre 2014 a 2018 (histórico) y se comparó con los casos observados a la misma semana epidemiológica del 2019. La razón esperada siempre será 1 y la significancia estadística estará dada por el valor de $p<0,05$ para identificar las entidades territoriales que presentan variaciones estadísticamente significativas.

\section{Mortalidad materna}

A semana epidemiológica 40 de 2019 se notificaron 367 muertes maternas: 236 tempranas (ocurridas durante el embarazo, parto y hasta los 42 días de terminada la gestación), 92 tardías (ocurridas desde el día 43 hasta un año de terminada la gestación) y 39 por causas coincidentes (lesiones de causa externa). Se han notificado 16 casos de mortalidad materna en mujeres residentes en el exterior.

En esta semana se notificaron 8 muertes maternas; 5 muertes maternas tempranas, 2 muertes maternas tardías y 1 muerte por lesión de causa externa (Tabla 3).

Tabla 3. Mortalidad materna según tipo de muerte, Colombia, semanas epidemiológicas 01 a 40, 2017 a 2019

\begin{tabular}{lcccc} 
& \multicolumn{3}{c}{ Tipo de muerte } & Total \\
\cline { 2 - 3 } & Temprana & Tardía & Coincidente & \\
2017 & 263 & 97 & 38 & 398 \\
2018 & 220 & 133 & 63 & 416 \\
2019 & 236 & 92 & 39 & 367 \\
\hline
\end{tabular}

Fuente: Sivigila, Instituto Nacional de Salud, Colombia, 2017-2019

La razón nacional preliminar de mortalidad materna a semana epidemiológica 40 es de 44,4 muertes por cada 100000 nacidos vivos. La razón de mortalidad materna superior a 100 muertes por cada 100000 nacidos vivos se observó en Vichada, Guainía, Vaupés, Buenaventura, La Guajira y Chocó (Tabla 4). 
Tabla 4. . Razón de mortalidad materna según entidad territorial de residencia, Colombia, semanas epidemiológicas 01 a 40 de 2019

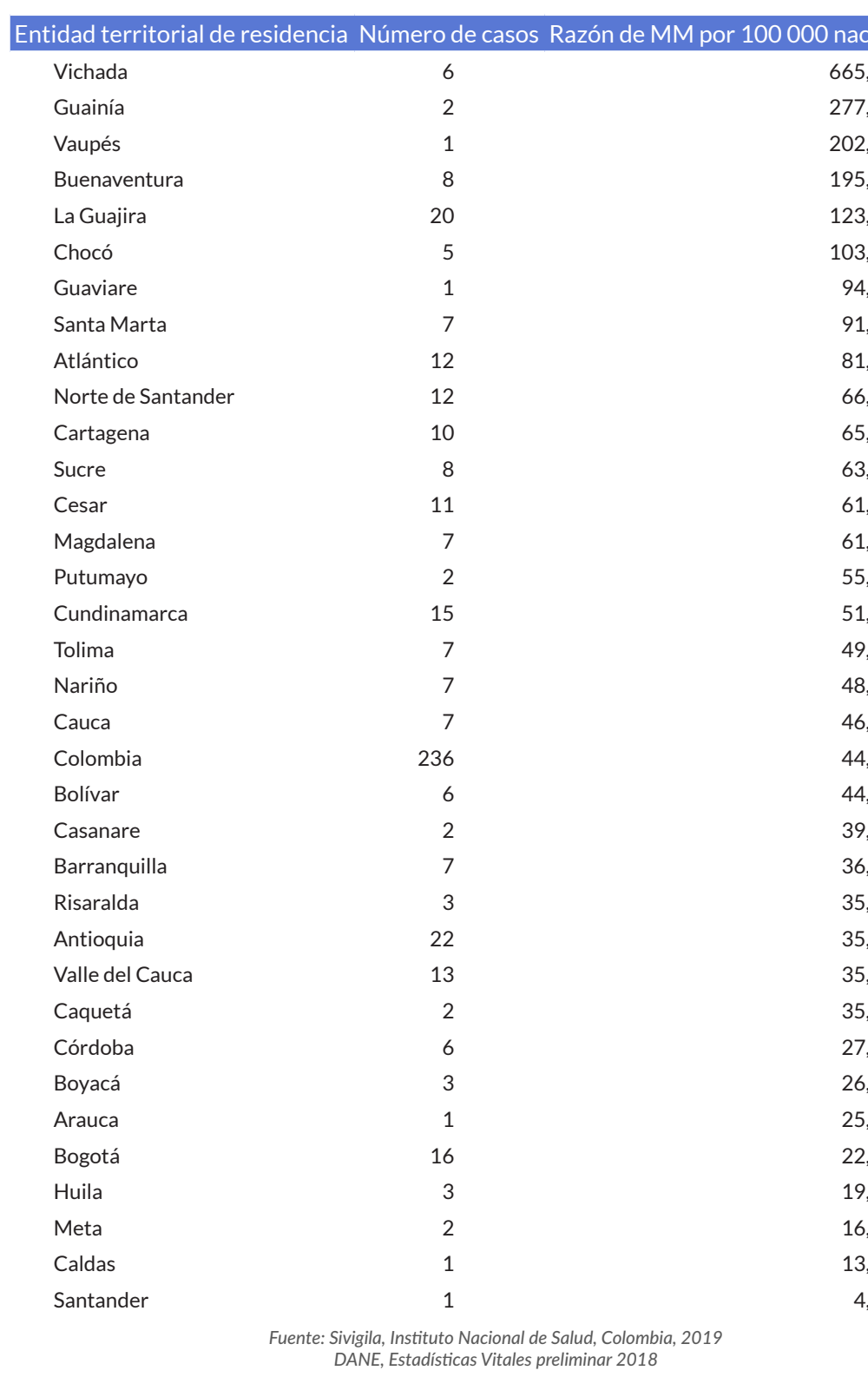

Para la semana epidemiológica 40 de 2019 se observó un aumento significativo en las muertes maternas tempranas comparado con el promedio histórico en la entidad territorial de Cartagena y Cundinamarca y disminución en las entidades territoriales de Bogotá y Córdoba (Tabla 5).

Tabla 5. Entidades territoriales con comportamientos inusuales de mortalidad materna temprana respecto al promedio 2014-2018, Colombia, semanas epidemiológicas 01 a 40 de $2019^{1}$

$\begin{array}{cccc}\text { Entidad territorial de residencia } & \text { Valor observado } & \text { Valor histórico } & \text { Poisson } \\ \text { Cartagena } & 10 & 6 & 0,041 \\ \text { Cundinamarca } & 15 & 10 & 0,035 \\ \text { Bogotá } & 16 & 22 & 0,040 \\ \text { Córdoba } & 6 & 17 & 0,001\end{array}$

Fuente: Sivigila, Instituto Nacional de Salud, Colombia, 2014-2019

En cuanto a las causas de muerte materna temprana el 47,5\% corresponden a causas directas y el $37,3 \%$ a causas indirectas. Las principales causas de muerte son los trastornos hipertensivos asociados al embarazo y hemorragia obstétrica con el 17,4 \% (Tabla 6).

Tabla 6. Mortalidad materna temprana por tipo y causa principal agrupada, Colombia, semanas epidemiológicas 01 al 40 de 2019

\begin{tabular}{lrr} 
Razón /Causa agrupada & Casos & \multicolumn{1}{c}{$\%$} \\
Directa & 112 & $\mathbf{4 7 , 5}$ \\
Trastorno hipertensivo asociado al embarazo & 41 & 17,4 \\
Hemorragia obstétrica & 41 & 17,4 \\
Otras causas directas & 10 & 4,2 \\
Sepsis relacionada con el embarazo & 10 & 4,2 \\
Embarazo terminado en aborto con causa directa: sepsis & 3 & 1,3 \\
Evento tromboembólico como causa básica & 5 & 2,1 \\
Embarazo terminado en aborto con causa directa: hemorragia & 2 & 0,8 \\
\hline Indirecta & $\mathbf{8 8}$ & $\mathbf{3 7 , 3}$ \\
Otras causas indirectas & 39 & 16,5 \\
Sepsis no obstétrica & 28 & 11,9 \\
Otra causa indirecta: VIH-SIDA & 5 & 2,1 \\
Otra causa indirecta: Tuberculosis & 4 & 1,7 \\
Evento tromboembólico como causa básica & 4 & 1,7 \\
Otra causa indirecta: Cáncer & 4 & 1,7 \\
Otra causa indirecta: Malaria & 2 & 0,8 \\
Otra causa indirecta: Accidente ofídico & 1 & 0,4 \\
\hline Otra causa indirecta:Dengue & 1 & 0,4 \\
\hline En estudio & $\mathbf{1}$ & $\mathbf{1 5 , 3}$
\end{tabular}

$\overline{1}$ Las demás entidades territoriales no presentaron comportamientos inusuales. 
Para el análisis de los comportamientos inusuales, por ser la mortalidad materna un evento de baja frecuencia, se hace uso de la distribución de probabilidades de Poisson por medio de la estimación de la probabilidad de ocurrencia del evento según su comportamiento medio entre el 2014 y 2018.

\section{Mortalidad perinatal y neonatal tardía}

A semana epidemiológica 40 de 2019, se han notificado 7176 casos de muerte perinatal y neonatal tardía (MPNT). En esta semana se notificaron 173 casos, de los cuales 130 corresponden a esta semana y 43 a notificaciones tardías.

Hasta la semana epidemiológica analizada la razón preliminar nacional de mortalidad perinatal y neonatal tardía es de 15,1 muertes por cada 1000 nacidos vivos, en la tabla 1 se observa que en 17 entidades territoriales la razón es superior a la del país. Las 5 entidades territoriales con las razones más altas son Vichada $(36,7)$, Chocó $(33,9)$, Buenaventura (30,5), Vaupés $(29,5)$ y La Guajira $(25,3)$ (Tabla 7$).$
Tabla 7. Número de casos y razón de mortalidad perinatal y neonatal tardía por entidad territorial de residencia, Colombia, semana epidemiológica 01 a 40 de 2019

\begin{tabular}{|c|c|c|}
\hline $\begin{array}{l}\text { Entidad territorial de } \\
\text { residencia }\end{array}$ & $\begin{array}{l}\text { Número de } \\
\text { casos }\end{array}$ & $\begin{array}{l}\text { Razón de Mortalidad perinatal y neonatal } \\
\text { tardía por } 1000 \text { nacidos vivos }\end{array}$ \\
\hline Vichada & 30 & 36,7 \\
\hline Chocó & 149 & 33,9 \\
\hline Buenaventura & 113 & 30,5 \\
\hline Vaupés & 13 & 29,5 \\
\hline La Guajira & 358 & 25,3 \\
\hline Amazonas & 21 & 21,9 \\
\hline Guainía & 12 & 18,7 \\
\hline Córdoba & 362 & 18,6 \\
\hline Guaviare & 17 & 18,1 \\
\hline Atlántico & 235 & 18,0 \\
\hline Barranquilla & 306 & 17,9 \\
\hline San Andrés y Providencia & 10 & 17,4 \\
\hline Sucre & 183 & 16,5 \\
\hline Nariño & 206 & 15,7 \\
\hline Magdalena & 156 & 15,4 \\
\hline Cesar & 241 & 15,3 \\
\hline Cauca & 204 & 15,1 \\
\hline Colombia & 7176 & 15,1 \\
\hline Bolívar & 181 & 15,0 \\
\hline Caldas & 97 & 15,0 \\
\hline Antioquia & 804 & 14,5 \\
\hline Santa Marta & 97 & 14,4 \\
\hline Norte de Santander & 230 & 14,2 \\
\hline Cartagena & 188 & 13,9 \\
\hline Meta & 151 & 13,7 \\
\hline Tolima & 172 & 13,6 \\
\hline Bogotá & 884 & 13,5 \\
\hline Putumayo & 44 & 13,4 \\
\hline Cundinamarca & 344 & 13,2 \\
\hline Caquetá & 66 & 13,0 \\
\hline Quindío & 54 & 13,0 \\
\hline Boyacá & 132 & 12,8 \\
\hline Valle del Cauca & 402 & 12,1 \\
\hline Risaralda & 89 & 11,8 \\
\hline Huila & 163 & 11,7 \\
\hline Arauca & 40 & 11,3 \\
\hline Casanare & 51 & 11,2 \\
\hline Santander & 194 & 9,0 \\
\hline Exterior & 177 & SD \\
\hline
\end{tabular}

Sivigila, Instituto Nacional de Salud, Colombia, 2019 (Datos preliminares). DANE, Estadísticas Vitales, Cifras preliminares nacimientos a julio 2018

Tema central
Situación Nal.
Mortalidad
Trazadores
Brotes
Sarampión
Tablas


Según el momento de ocurrencia de la muerte, la mayor proporción son muertes perinatales anteparto con 48,4\% (3472), seguido de neonatales tempranas con $27,8 \%$ (1997), neonatales tardías con $14,2 \%$ (1016) y perinatales intraparto con 9,6\% (691).

De acuerdo con las causas de muerte agrupadas, se observó la mayor proporción en: otras causas de muerte $24,6 \%$ principalmente trastornos de origen neonatal; seguido por prematuridad-inmaturidad 24,2 $\%$ y asfixia y causas relacionadas $22,1 \%$ (Figura 6).

Figura 6. Proporción de causas de muertes perinatales y neonatales tardías por causas de muerte agrupadas, Colombia, semana epidemiológica 01 a 40 de 2019

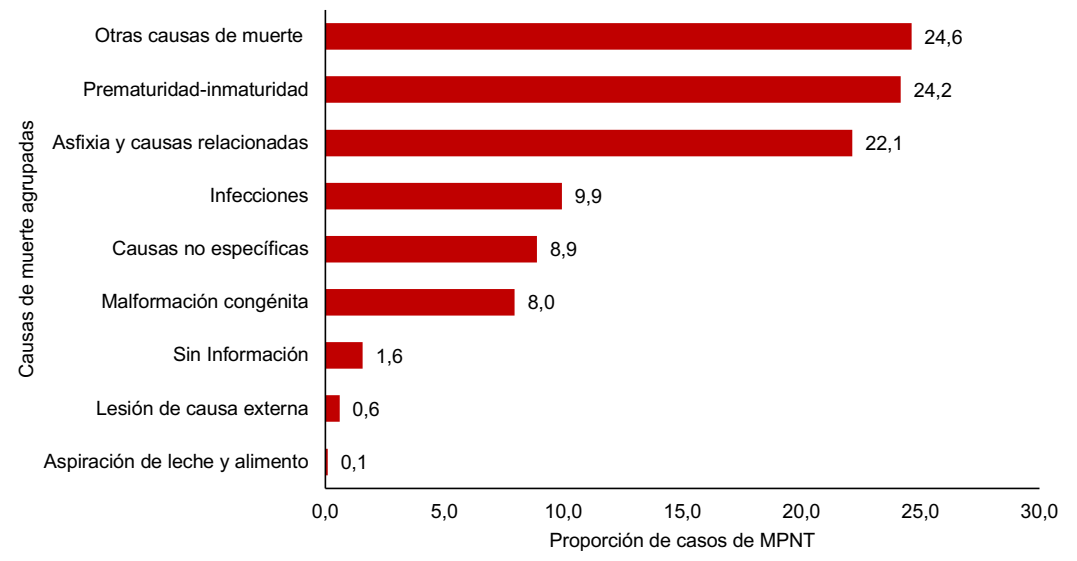

Fuente: Sivigila, Instituto Nacional de Salud, Colombia, 2019 (Datos preliminares).
En lo observado hasta la semana 40 de 2019, en comparación con lo notificado entre 2014 y 2018 , se presenta un decremento en la notificación en Cesar, Santander y Valle. Comportamiento que podría ser explicado por el subregistro en la notificación de las muertes a Sivigila, respecto al número de muertes certificadas en el Registro Único de Afiliados a la Protección Social-RUAF.

Dado que el evento tiene una alta frecuencia en notificación y se cuenta con una línea de base estable de más de cinco años, se realiza el análisis de los comportamientos inusuales a través del método: Morbidity and Mortality Weekly Report (MMWR) del Center for Disease Control and Prevention (CDC). Este se basa en la comparación del comportamiento actual del evento en el último periodo epidemiológico (valor observado) con el resultado del promedio de 15 periodos históricos alrededor de ese periodo de evaluación, la ventana histórica de estimación contempla los cinco años previos al año de análisis (Coutin G, Borges J, Batista R, Feal P, Suárez B. Método para el análisis del comportamiento observado de enfermedades seleccionadas con relación al comportamiento histórico. Rev Cubana Hig Epidemiol 2000;38(3):157-66)
Tema central

Situación Nal.

Mortalidad

Trazadores

Brotes

Sarampión

Tablas 


\section{EVENTOS TRAZADORES}

\section{Infección respiratoria aguda}

\section{Vigilancia centinela de enfermedad similar a la influenza e infección respiratoria aguda grave}

En la semana epidemiológica 40 de 2019 se notificaron 100 casos de enfermedad similar a la influenza (ESI) e infección respiratoria aguda grave (IRAG), 45 de esta semana y 55 de semanas anteriores, por lo cual se presenta un ajuste en el número de casos de la semana 39; el 78,0 \% (78) se presentó en pacientes con infección respiratoria aguda grave y el $22,0 \%$ (22) en pacientes con enfermedad similar a la influenza. A la fecha han ingresado 4897 casos mediante la estrategia de vigilancia centinela.

Para la semana epidemiológica 40 la notificación de este evento se encuentra por debajo del límite inferior histórico y del umbral estacional (promedio de notificación semanal de casos entre 2012 y 2018). Para las últimas semanas la notificación de este evento se encuentra dentro de lo esperado para esta época del año en el país (Figura 7).

Figura 7. Canal endémico de enfermedad similar a la influenza e infección respiratoria aguda grave en Colombia, semanas epidemiológicas 01 a 40, entre 2012 y 2019

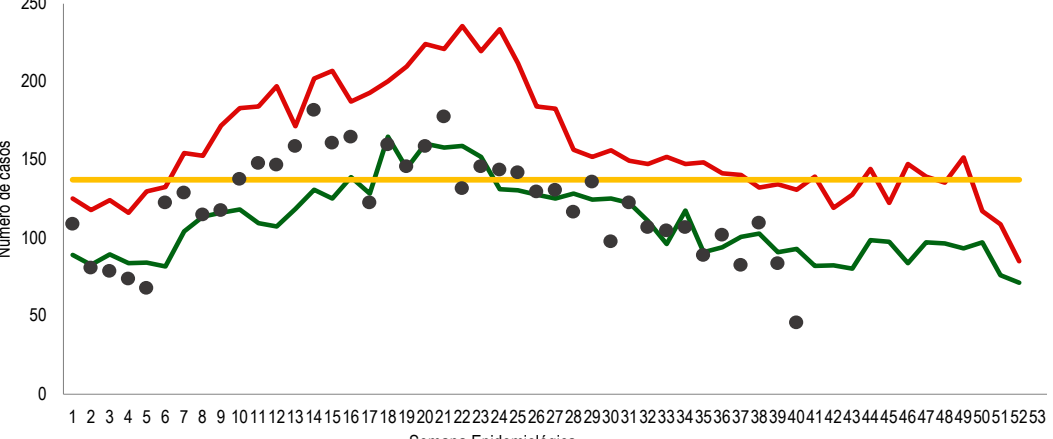
Semana Epidemiológica

$$
\text { }
$$$$
\text { Semana Epidemilóggica }
$$

El distrito de Barranquilla y el departamento del Tolima no notificaron casos durante esta semana; en la tabla se presenta el número de casos notificados por cada institución centinela (Tabla 8).

Tabla 8. Casos notificados de enfermedad similar a la influenza e infección respiratoria aguda grave por entidad territorial e institución centinela en Colombia, semana epidemiológica 40 de 2019

\begin{tabular}{llr} 
Entidad Territorial & Institución centinela & Casos \\
Antioquia & Fundación Hospitalaria San Vicente de Paúl & 10 \\
Barranquilla & Clínica General del Norte & 0 \\
Bogotá D.C. & Hospital el Tunal & 3 \\
& Fundación Cardioinfantil & 17 \\
Cartagena & Hospital Infantil Napoleón Franco Pareja & 11 \\
Guaviare & Laboratorio Departamental de Salud Pública & 16 \\
Meta & Hospital Departamental de Villavicencio & 7 \\
Nariño & Fundación Hospital San Pedro & 6 \\
& Hospital Infantil Los Ángeles & 7 \\
Norte de Santander & Hospital Universitario Erasmo Meoz & 10 \\
Tolima & Hospital Federico Lleras Acosta & 0 \\
Valle del Cauca & Fundación Valle del Lili & 13 \\
\hline & $\quad$ Total & 100 \\
\hline
\end{tabular}

Fuente: Sivigila, Instituto Nacional de Salud, Colombia, 2019

\section{Vigilancia de infección respiratoria aguda grave inusitada}

En la semana epidemiológica 40 de 2019 se notificaron 26 casos de infección respiratoria aguda grave inusitada, 16 de esta semana y 10 de semanas anteriores; durante esta semana se descartaron 6 casos por no cumplir con la definición del evento. A la fecha han ingresado 664 casos sin identificar virus nuevos o de alta patogenicidad.

El comportamiento de la notificación de este evento se encuentra por debajo del promedio histórico de las semanas 01 a 52 de 2018 (figura 8).

\begin{tabular}{l} 
Tema central \\
Situación Nal. \\
\hline Mortalidad \\
\hline Trazadores \\
\hline Brotes \\
\hline Sarampión \\
\hline Tablas
\end{tabular}


Figura 8. Comportamiento de la notificación de infección respiratoria aguda grave inusitada en Colombia, semanas epidemiológicas 01 a 40 de 2019

50

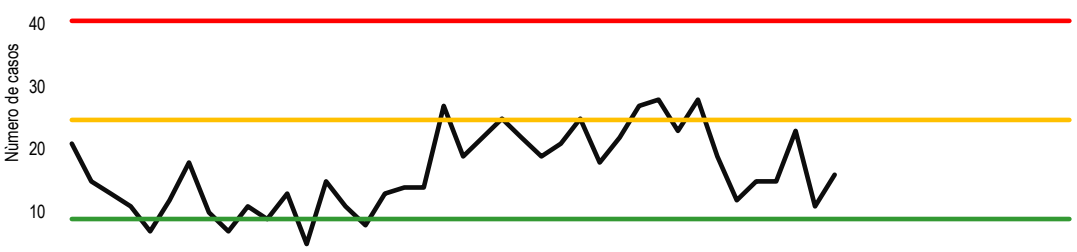

123456789101112131415161718192021222324252627282930313233343536373839404142434445464748495051 Semana epidemilobgica

Fuente: Sivigila, Instituto Nacional de Salud, Colombia, 2019

\section{Vigilancia de morbilidad por infección respiratoria aguda}

A nivel nacional se identifica disminución de la morbilidad por infección respiratoria aguda (IRA) en los tres servicios, especialmente para las hospitalizaciones en sala general (tabla 9).

Tabla 9. Notificación morbilidad por Infección Respiratoria Aguda por tipo de servicio en Colombia, semanas epidemiológicas 01 a 40, 2019

\begin{tabular}{lrrrc} 
Tipo de servicio & 2018 a semana 40 & 2019 a semana 40 & Variación \\
\hline Consultas ambulatorias y urgencias & 5483657 & 5196943 & $5,2 \%$ & Disminución \\
Hospitalizaciones en sala general & 194322 & 177181 & $8,8 \%$ Disminución \\
Hospitalizaciones en UCl & 17716 & 16524 & $6,7 \%$ Disminución
\end{tabular}

Fuente: Sivigila, Instituto Nacional de Salud, Colombia, 2018 a 2019

Las consultas externas y urgencias por IRA aumentaron a partir de la semana epidemiológica 08 superando el umbral estacional; para las semanas 28, 29, 31 y 35 se superó el límite superior (figura 9).
Figura 9. Canal endémico de consultas externas y urgencias por infección respiratoria aguda, Colombia, semanas epidemiológicas 01 a 40, entre 2013 y 2019

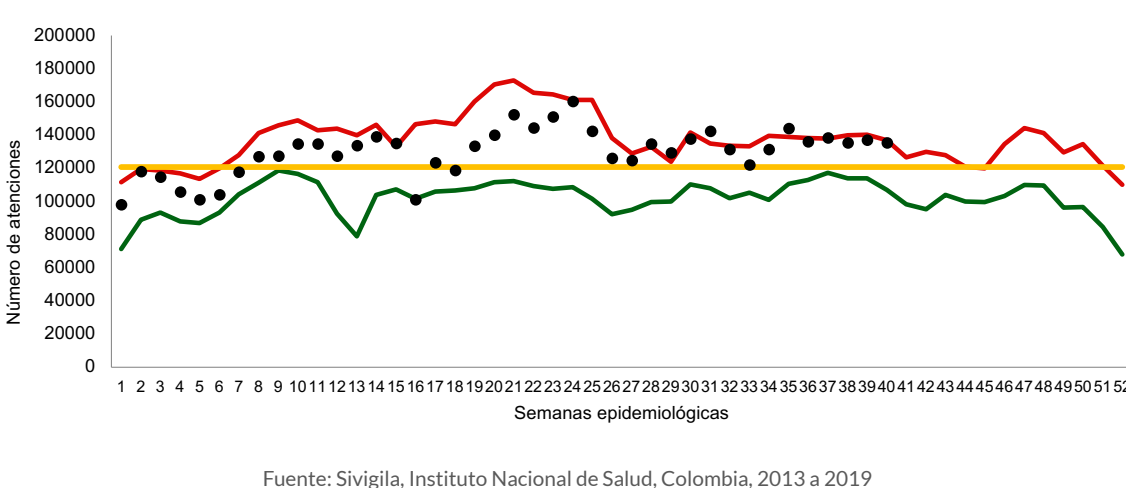

Las hospitalizaciones por IRAG en sala general se han comportado durante todo el año dentro de los límites históricos esperados; se superó el umbral estacional a partir de la semana epidemiológica 13 hasta la semana 32 (figura 10).

Figura 10. Canal endémico de hospitalizaciones por infección respiratoria aguda grave en sala general, Colombia, semanas epidemiológicas 01 a 40, entre 2013 y 2019

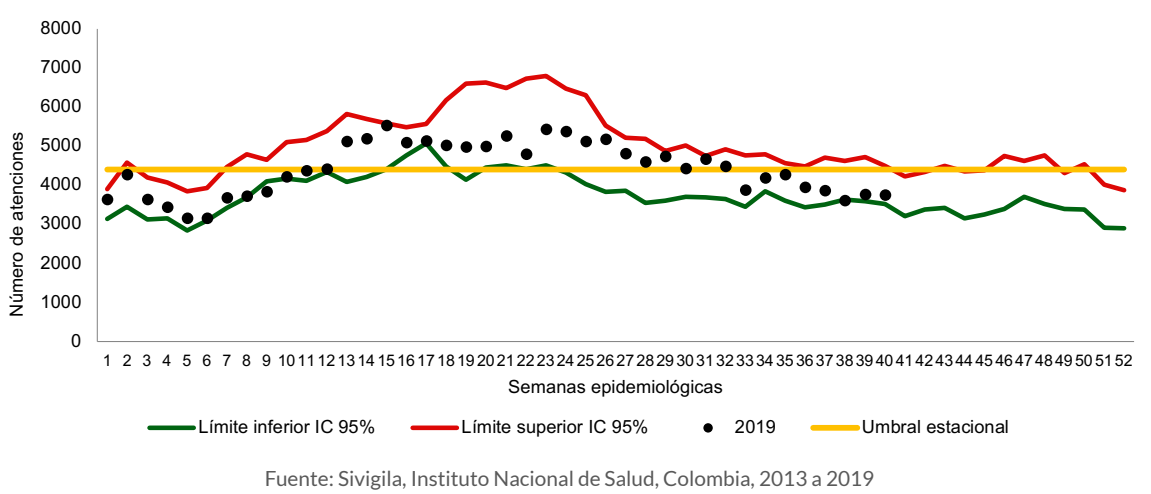

Este año las hospitalizaciones por IRAG en unidades de cuidados intensivos han superado el umbral estacional durante todo el año y el límite superior durante 22 semanas epidemiológicas (figura 11).

\section{Tema central \\ Situación Nal.}

Mortalidad

Trazadores

Brotes

Sarampión

Tablas 
Figura 11. Canal endémico de hospitalizaciones por infección respiratoria aguda grave en unidades de cuidados intensivos, Colombia, semanas epidemiológicas 01 a 40, entre 2013 y 2019

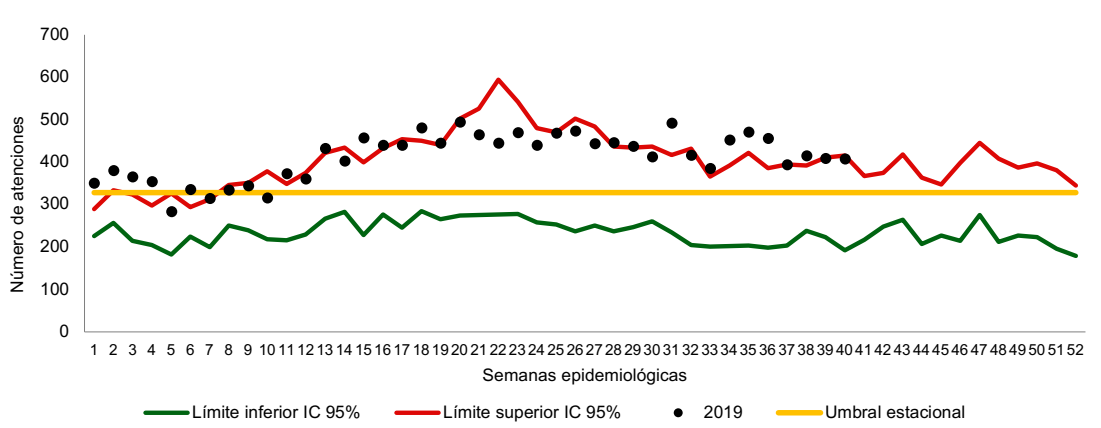

Fuente: Sivigila, Instituto Nacional de Salud, Colombia, 2013 a 2019

En las hospitalizaciones por IRAG en unidades de cuidados intensivos, los menores de 1 año representanel 36,0\%(5946), seguido por los adultos de 60 años y más con el 30,5\% (5047). La mayor proporción de hospitalizaciones por IRAG en UCI sobre el total de hospitalizaciones por todas las causas se presenta en los niños de 1 año con el 22,1\% (1 200 / 5 438).

\section{Metodología:}

Vigilancia centinela: en la elaboración del canal endémico se utilizó como dato de entrada, el número de casos de ESI-IRAG notificados por semana epidemiológica mediante la técnica de Bortman; se calculó el umbral estacional teniendo en cuenta el promedio de notificación por semana epidemiológica de los años 2012 a 2018 y se definieron los límites de control que permitieran evidenciar el riesgo de epidemia.

Vigilancia IRAG inusitado: para este análisis de comportamientos inusuales, los casos observados corresponden a lo notificado entre las semanas 37 a 40 de 2019 y los casos esperados al promedio de notificación, entre las semanas epidemiológicas 01 a 52 de 2018. Se calculó la razón dividiendo los casos observados sobre los casos esperados; la razón esperada siempre será 1 y la significancia estará dada por el valor de $(p<0,05)$, para identificar las entidades territoriales que presentan diferencias estadísticamente significativas entre lo observado y sus valores esperados.

Vigilancia morbilidad por IRA: los canales endémicos se realizaron con la metodología de Bortman con los datos de la morbilidad por infección respiratoria aguda mediante el cálculo de la media geométrica de los años 2013 a 2018 y su intervalo de confianza.

\section{Chikungunya}

A semana epidemiológica 40 de 2019 se han notificado 441 casos de chikungunya, para esta semana ingresaron 7 casos, 3 de esta semana y 4 de semanas anteriores. A la fecha se han reportado, $356(80,7 \%)$ confirmados por clínica, 43 (9,8 \%) confirmados por laboratorio y $42(9,5$ $\%)$ sospechosos. Existe un descenso en la notificación del evento del 19,2 \%, 105 casos menos, comparado con el mismo periodo analizado de 2018. El 11,6 \% (51) de los casos pertenece a los grupos de riesgo, 3,4 \% (15) gestantes, 5,2 \% (23) menores de 5 años y 2,9\% (13) mayores de 65 años.

El 55,8 \% (246) de los casos procede de Putumayo, Cundinamarca, Santander, Tolima, Valle del Cauca y Antioquia. La incidencia a nivel nacional es de 1,64 casos por cada 100000 habitantes en riesgo y las entidades territoriales que registran las incidencias más altas son: Putumayo (36 casos por cada 100000 habitantes) y Amazonas (24 casos por cada 100000 habitantes). El comportamiento de la notificación a semana epidemiológica 40 de 2019, se encuentra por debajo del promedio histórico de 2017 y 2018; sin embargo, se observa que, durante las semanas epidemiológicas 13 y 28 se presentó el mayor número de casos ubicándose por encima del promedio histórico (figura 1). A semana epidemiológica 40 Amazonas, Nariño, Putumayo y Sucre presentan un aumento significativo de casos por encima de lo esperado (Figura 12).

Figura 12. Comportamiento de la notificación de Chikungunya en Colombia, semanas epidemiológicas 01 a 40 de 2019
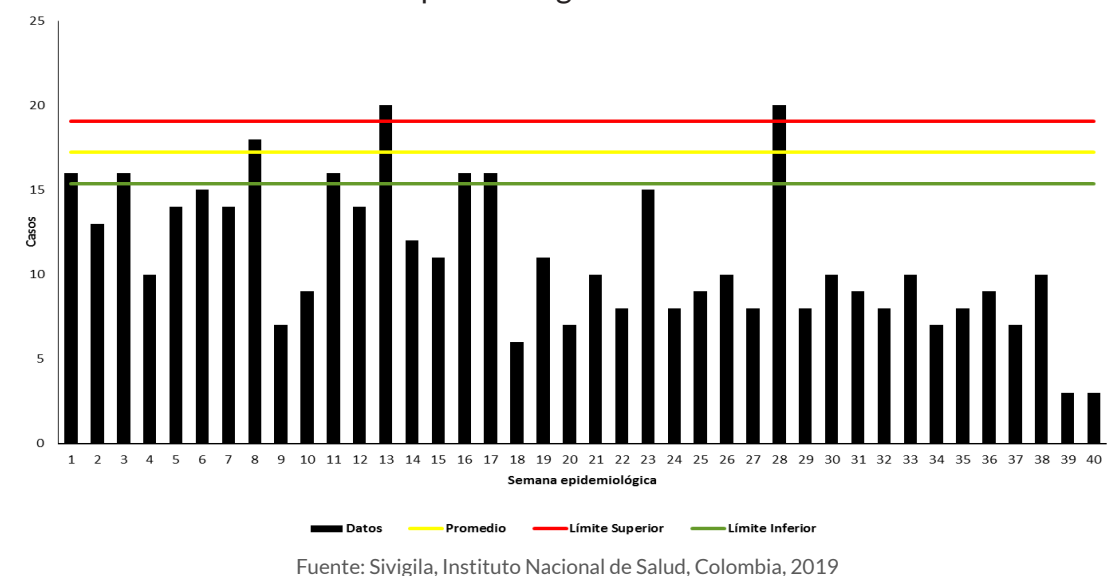

Tema centra

Situación Nal.

Mortalidad

Trazadores

Brotes

Sarampión

Tablas 


\section{Enfermedad por virus Zika}

Para este año se han notificado 347 casos de enfermedad por virus Zika, $262(75,5 \%)$ confirmados por clínica, 11 (3,2 \%) confirmados por laboratorio y $74(21,3 \%)$ sospechosos. Existe un descenso en la notificación del evento del 51,1\%, 363 casos menos, comparado con el mismo periodo de 2018. A semana epidemiológica 40 se han notificado $95(27,4 \%)$ casos que pertenecen a los grupos de riesgo, 12,7 \% (44) gestantes, 13,3\% (46) menores de un año y 1,4\% (5) mayores de 65 años.

El 66,0\% (229) de los casos procede de las entidades territoriales de Putumayo, Valle del Cauca, Meta, Santander, Cundinamarca y Tolima. La incidencia a nivel nacional es de 1,33 casos por cada 100000 habitantes en riesgo, las incidencias más altas registradas corresponden a Putumayo (41,21 casos por cada 100000 habitantes) y Amazonas ( 24 casos por cada 100000 habitantes). El comportamiento de la notificación del evento en 2019, se encuentra por debajo del promedio histórico de 2017 y 2018 (figura 2). Asimismo, se observó que, a esta semana Putumayo presenta un aumento significativo por encima de lo esperado (Figura 13).

Figura 13. Comportamiento de la notificación de enfermedad por virus Zika en Colombia, semanas epidemiológicas 01 a 40 de 2019

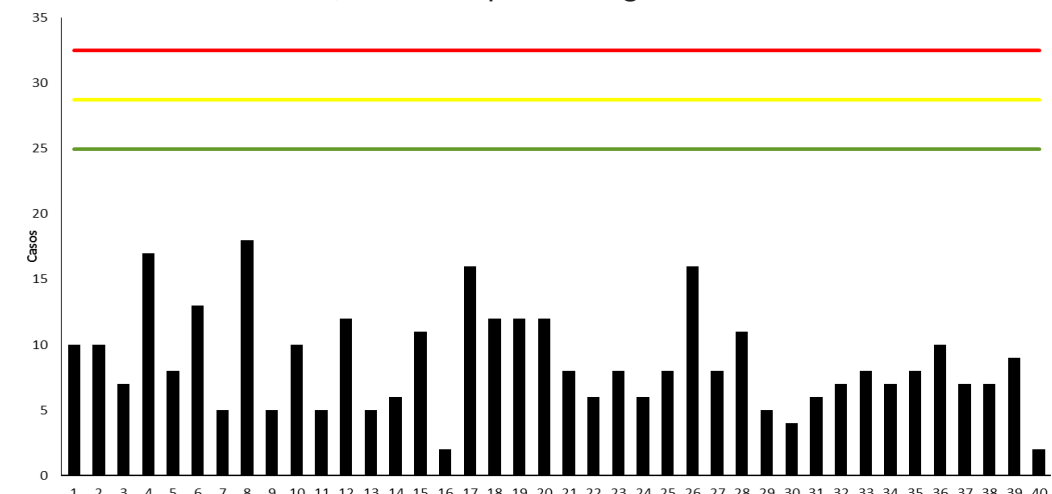

Fuente: Sivigila, Instituto Nacional de Salud, Colombia, 2019

\section{Dengue}

En la semana epidemiológica 40 de 2019 se notificaron 2243 casos probables de dengue; 1176 de esta semana y 1067 de otras semanas. En el sistema hay 96788 casos, 46716 (48,3\%) sin signos de alarma, $49043(50,7 \%)$ con signos de alarma y $1029(1,1 \%)$ de dengue grave.

Por procedencia, los departamentos de Meta, Tolima, Huila, Santander, Norte de Santander, Cesar, Casanare, y Antioquia aportan el 65,1\% (63 035) de los casos de dengue a nivel nacional (Tabla 10).

Tabla 10. Casos notificados de dengue por entidad territorial de procedencia y clasificación en Colombia durante las semanas epidemiológicas 01 a 40 de 2019

\begin{tabular}{|c|c|c|c|c|c|c|}
\hline \multirow{2}{*}{ Entidad territorial } & \multicolumn{2}{|c|}{ Dengue } & \multicolumn{4}{|c|}{ Dengue grave Total } \\
\hline & $\bar{n}$ & $\%$ & $\mathrm{n}$ & $\%$ & $\bar{n}$ & $\%$ \\
\hline Meta & 14929 & 15,6 & 116 & 11,3 & 15045 & 15,5 \\
\hline Tolima & 10429 & 10,9 & 68 & 6,6 & 10497 & 10,8 \\
\hline Huila & 8916 & 9,3 & 242 & 23,5 & 9158 & 9,5 \\
\hline Santander & 7585 & 7,9 & 31 & 3,0 & 7616 & 7,9 \\
\hline Norte de Santander & 5650 & 5,9 & 41 & 4,0 & 5691 & 5,9 \\
\hline Cesar & 5079 & 5,3 & 48 & 4,7 & 5127 & 5,3 \\
\hline Casanare & 5044 & 5,3 & 37 & 3,6 & 5081 & 5,2 \\
\hline Antioquia & 4787 & 5,0 & 33 & 3,2 & 4820 & 5,0 \\
\hline Sucre & 4671 & 4,9 & 73 & 7,1 & 4744 & 4,9 \\
\hline Valle del Cauca & 3577 & 3,7 & 27 & 2,6 & 3604 & 3,7 \\
\hline Córdoba & 3391 & 3,5 & 34 & 3,3 & 3425 & 3,5 \\
\hline Cundinamarca & 2753 & 2,9 & 23 & 2,2 & 2776 & 2,9 \\
\hline Magdalena & 2388 & 2,5 & 52 & 5,1 & 2440 & 2,5 \\
\hline Bolívar & 2196 & 2,3 & 41 & 4,0 & 2237 & 2,3 \\
\hline Arauca & 1878 & 2,0 & 18 & 1,7 & 1896 & 2,0 \\
\hline Putumayo & 1634 & 1,7 & 10 & 1,0 & 1644 & 1,7 \\
\hline Atlántico & 1297 & 1,4 & 17 & 1,7 & 1314 & 1,4 \\
\hline Amazonas & 1022 & 1,1 & 2 & 0,2 & 1024 & 1,1 \\
\hline Cartagena & 974 & 1,0 & 19 & 1,8 & 993 & 1,0 \\
\hline Boyacá & 871 & 0,9 & 5 & 0,5 & 876 & 0,9 \\
\hline La Guajira & 825 & 0,9 & 12 & 1,2 & 837 & 0,9 \\
\hline Barranquilla & 769 & 0,8 & 15 & 1,5 & 784 & 0,8 \\
\hline Caquetá & 675 & 0,7 & 9 & 0,9 & 684 & 0,7 \\
\hline Santa Marta & 572 & 0,6 & 15 & 1,5 & 587 & 0,6 \\
\hline Exterior & 514 & 0,5 & 8 & 0,8 & 522 & 0,5 \\
\hline Guaviare & 510 & 0,5 & 3 & 0,3 & 513 & 0,5 \\
\hline Caldas & 468 & 0,5 & 5 & 0,5 & 473 & 0,5 \\
\hline Nariño & 440 & 0,5 & 2 & 0,2 & 442 & 0,5 \\
\hline Quindío & 356 & 0,4 & 2 & 0,2 & 358 & 0,4 \\
\hline Vichada & 351 & 0,4 & 1 & 0,1 & 352 & 0,4 \\
\hline Cauca & 309 & 0,3 & 10 & $\begin{array}{l}1,0 \\
1,0\end{array}$ & 319 & 0,3 \\
\hline Risaralda & 314 & 0,3 & 2 & 0,2 & 316 & 0,3 \\
\hline Chocó & 176 & 0,2 & 3 & 0,3 & 179 & 0,2 \\
\hline Vaupés & 161 & 0,2 & 2 & 0,2 & 163 & 0,2 \\
\hline Guainía & 151 & 0,2 & 0 & 0,0 & 151 & 0,2 \\
\hline Buenaventura & 67 & 0,1 & 3 & 0,3 & 70 & 0,1 \\
\hline Archipiélago de San Andrés & 27 & 0,0 & 0 & 0,0 & 27 & 0,0 \\
\hline Desconocido & 3 & 0,0 & 0 & 0,0 & 3 & 0,0 \\
\hline Total & 95759 & 100,0 & 1029 & 100,0 & 96788 & 100,0 \\
\hline
\end{tabular}

Fuente: Sivigila, Instituto Nacional de Salud, Colombia, 2019 


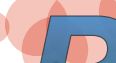 BES \\ Boletín Epidemiológico Semanal}

El 51,3\% (49 668) de los casos es de sexo masculino, 54,4\% (52 626) pertenece al régimen subsidiado y 4,0\% (3 826) refiere no afiliación; el 15,8 \% (15 178) de dengue y el 25,0\% (257) de dengue grave se presentó en menores de 5 años. Hay 1,3\% (1 224) en población indígena, 1,6\% (1 520) en afrocolombianos, 0,3 \% (280) ROM-Gitano, $0,1 \%(100)$ raizal y $0,02 \%$ (22) palenquero. El 2,4 \% (390) de los casos en mujeres en edad fértil se encuentra en gestación.

A semana 40 los casos de dengue proceden de 32 entidades territoriales, 4 distritos, 788 municipios y 17 países del exterior. El 50,3\% (48 204) de los casos de dengue se reportó en 31 municipios, con mayor frecuencia en: Villavicencio, con 7,4 \% (7 111); Neiva, con 5,2 \% (4 998); Cúcuta, con 3,4 \% (3 241); Ibagué, con 3,2 \% (3 098); Sincelejo, con 2,8 \% (2 678); Yopal, con 2,2 \% (2 079); Cali (2 023) y Bucaramanga (1 982), con $2,1 \%$ cada uno; Valledupar, con 1,7 \% (1 625); Espinal, con 1,6 \% (1 566); y Acacías, con 1,5\% (1 421); Montería, con 1,4 \% (1 368); Medellín (1 037) y Granada (1 036), con $1,1 \%$ cada uno (Figura 14).
Figura 14. Municipios con mayor número de casos de dengue, Colombia, semanas epidemiológicas 01 a 40 de 2019

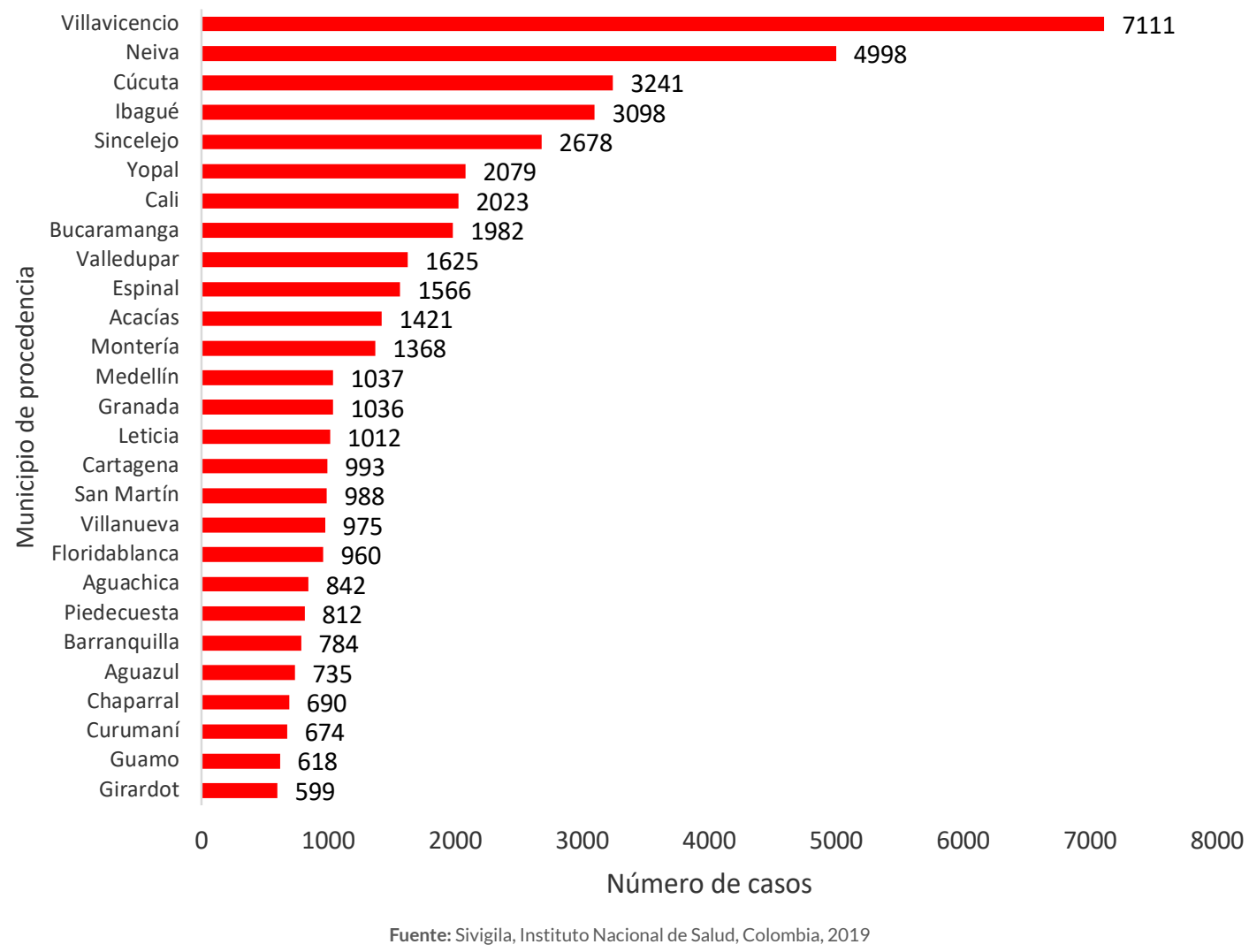




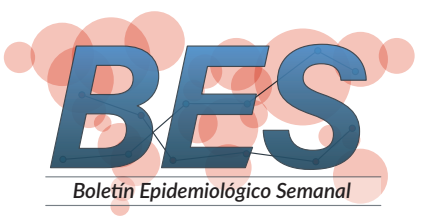

El 55,5\% (571) de los casos de dengue grave procede de 33 municipios, con mayor frecuencia de: Neiva, con 13,1\% (135); Villavicencio, con 5,2 \% (53); Sincelejo, con 2,7\% (28); Cúcuta, con 2,5 \% (26); Granada y Aguachica, con 2,1\% (22) cada uno; Cartagena y Palermo, con 1,8 \% (19) cada uno; Ibagué, con 1,7\% (18); Plato, con 1,6\% (16); Barranquilla, Santa Marta y Villanueva, con 1,5\% (15) cada uno.

Se hospitalizó el 78,7 \% (38 609) de los casos de dengue con signos de alarma; las entidades notificadoras que hospitalizaron menos del $60,0 \%$ de estos casos fueron: Santa Marta, Antioquia, Bolívar, Quindío, Buenaventura y Guainía (Figura 15).

De dengue grave fueron hospitalizados 1002 casos (97,4\%); las entidades que no hospitalizaron el $100,0 \%$ de casos de dengue grave notificados fueron: Tolima, Meta, Huila, Valle del Cauca, Atlántico, Santander, Córdoba, Putumayo, Santa Marta, Magdalena, Buenaventura, Bolívar y Cauca (figura 16).
Figura 15. Proporción de hospitalización de casos de dengue con signos de alarma por entidad notificadora en Colombia, semanas epidemiológicas 01 a 40 de 2019

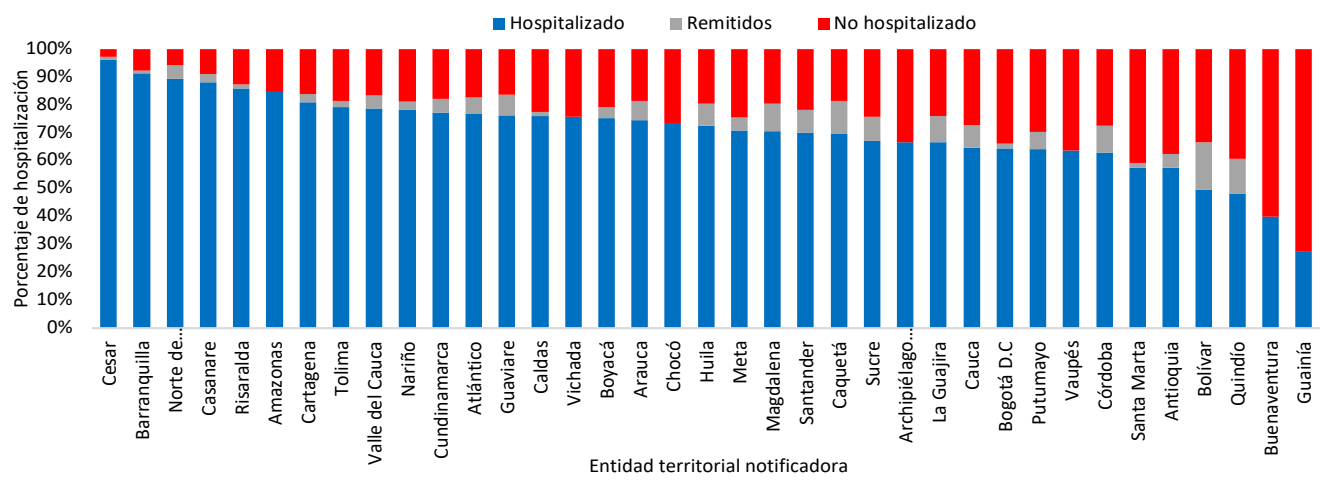

Fuente: Sivigila, Instituto Nacional de Salud, Colombia, 2019

Figura 16. Proporción de hospitalización de casos de dengue grave por entidad notificadora en Colombia, semanas epidemiológicas 01 a 40 de 2019

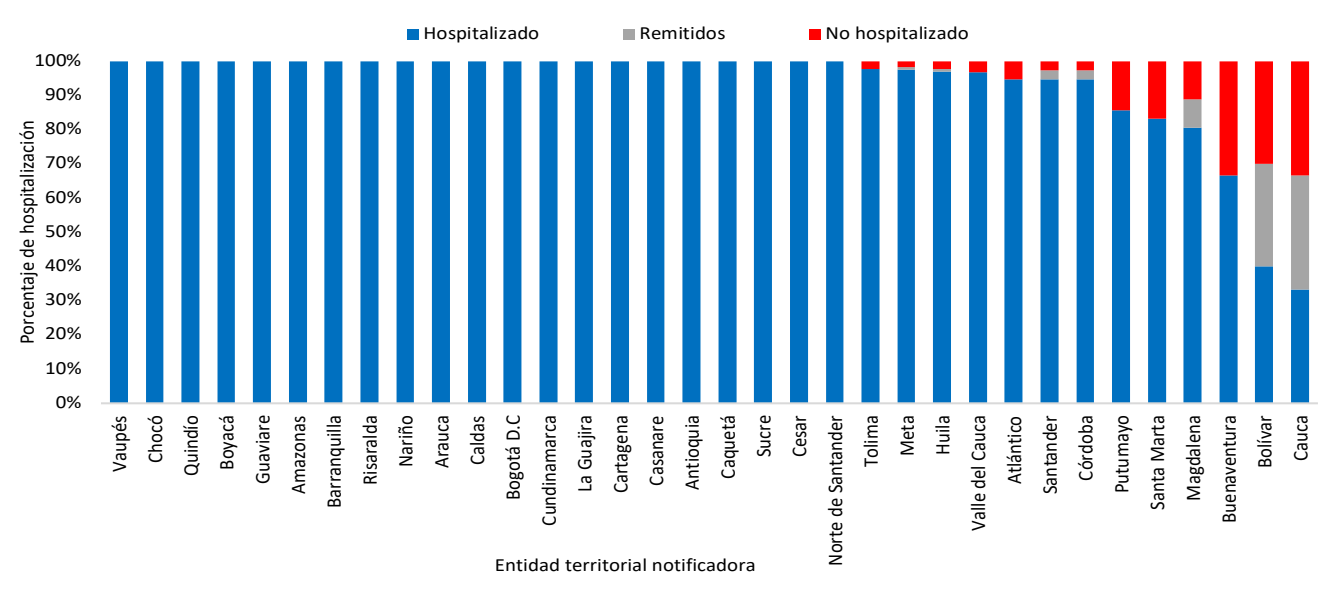

Fuente: Sivigila, Instituto Nacional de Salud, Colombia, 2019

Tema central
Situación Nal.
Mortalidad
Trazadores
Brotes
Sarampión
Tablas


A semana 40 se ha confirmado el $54,3 \%$ ( 26 649) de los casos de dengue con signos de alarma, las entidades que han confirmado más del 90,0\% de los casos notificados son Archipiélago de San Andrés y Providencia, Bogotá, Buenaventura, Chocó y Córdoba. Por otro lado, se ha confirmado el 67,8 \% (698) de los casos de dengue grave y las entidades con el 100,0 \% de los casos confirmados son Amazonas, Barranquilla, Bogotá, Boyacá, Buenaventura, Caldas, Caquetá, Cauca, Chocó, Guaviare y Quindío.

La incidencia nacional de dengue es de 360,7 casos por cada 100000 habitantes en riesgo. Para los departamentos de Amazonas, Meta, Casanare, Huila, Guainía, Arauca, Tolima, Putumayo, Vichada, Vaupés, Sucre, Boyacá, Guaviare, Cesar, Cundinamarca, Norte de Santander y Magdalena se estiman tasas de incidencia superiores a 500 casos por 100000 habitantes (figura 17).

En las semanas 01 a 07 el evento se ubicó en situación de alerta y desde la semana 08 presenta un comportamiento por encima del número esperado de casos a nivel nacional, comparado con su comportamiento histórico (20112018), lo que ubica al país en situación de epidemia (figura 18).
Figura 17. Incidencia de dengue por entidad territorial de procedencia en Colombia, semanas epidemiológicas 01 a 40 de 2019

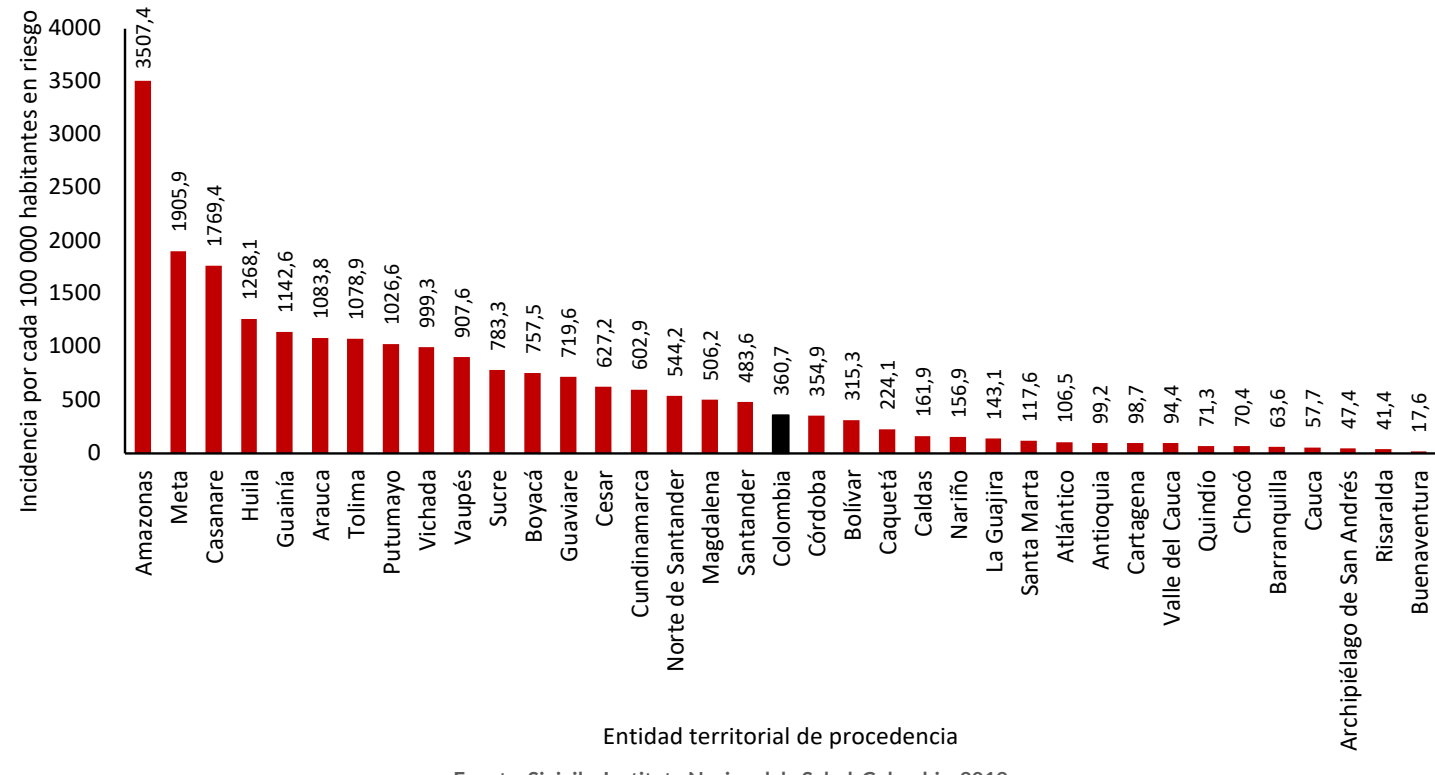

Fuente: Sivigila, Instituto Nacional de Salud, Colombia, 2019

Figura 18. Canal endémico nacional de dengue en Colombia, semanas epidemiológicas 01 a 40 de 2019

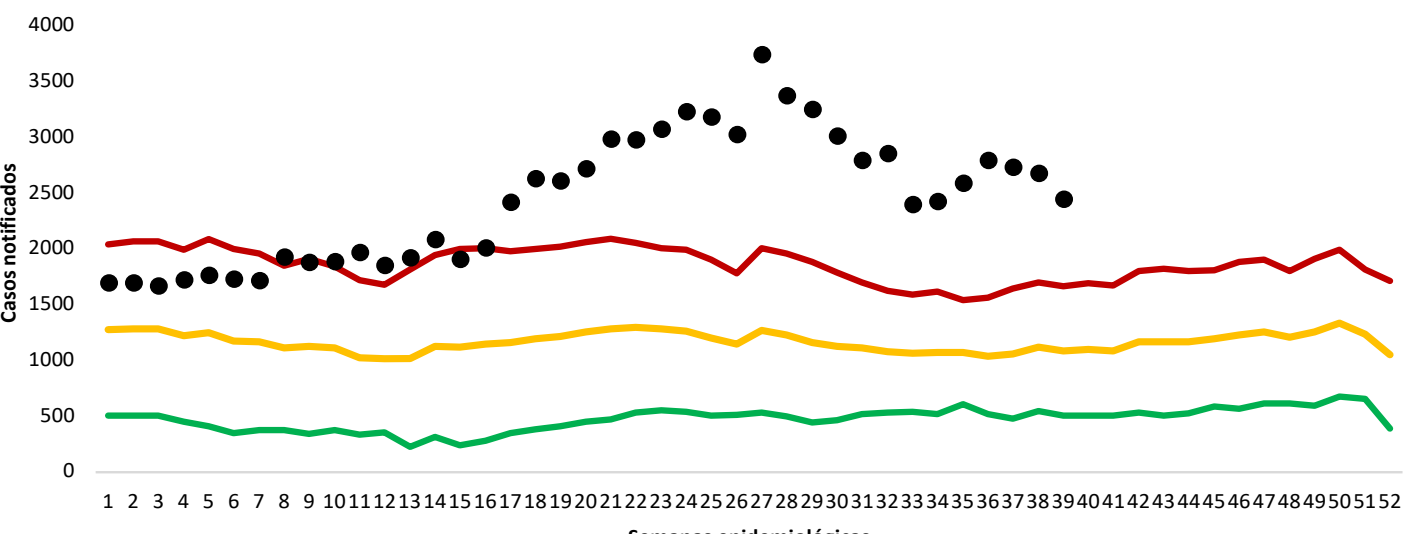
Semanas epidemiológicas

Fuente: Sivigila, Instituto Nacional de Salud, Colombia, 2019

\begin{tabular}{l} 
Tema central \\
\hline Situación Nal. \\
Mortalidad \\
\hline Trazadores \\
Brotes \\
Sarampión \\
\hline
\end{tabular}

Tablas 
De acuerdo con la situación epidemiológica, 3 entidades presentaron un comportamiento dentro de lo esperado, 11 entidades territoriales se ubicaron en situación de alerta y 22 entidades territoriales con presentación de casos por encima del valor esperado, comparado con el comportamiento histórico (2011-2018) (Tabla 11).

Tabla 11. Comparación de los casos notificados de dengue con su comportamiento histórico (2011 - 2018), por entidad territorial de procedencia en Colombia, semanas epidemiológicas 39 y 40 de 2019

\begin{tabular}{llll}
\hline $\begin{array}{l}\text { Comportamiento } \\
\text { epidemiológico }\end{array}$ & Entidad territorial & & \\
$\begin{array}{l}\text { Dentro del número } \\
\text { esperado de casos }\end{array}$ & $\begin{array}{l}\text { Quindío } \\
\text { Buenaventura }\end{array}$ & $\begin{array}{l}\text { San Andrés, Providenciay y } \\
\text { Santa Catalina }\end{array}$ & \\
\hline Situación de alerta & Antioquia & Barranquilla & Santa Marta \\
& Cauca & La Guajira & Guainía \\
& Guaviare & Risaralda & Putumayo \\
\hline Norte de Santander & Valle del Cauca & \\
número esperado & Amazonas & Arauca & Casanare \\
de casos & Atlántico & Boyacá & Bolívar \\
& Cartagena & Caldas & Cesar \\
& Cundinamarca & Caquetá & Córdoba \\
& Chocó & Magdalena & Meta \\
& Huila & Nariño & Santander \\
& Sucre & Tolima & Vaupés \\
& Vichada & & \\
\hline & Fuente: Sivigila, Instituto Nacional de Salud, Colombia 2019 &
\end{tabular}

Durante el 2019 se han notificado 190 muertes probables por dengue, de las cuales 65 han sido confirmadas procedentes de: Meta, con 14 casos; Atlántico y Tolima, con 7 casos cada uno; Bolívar y Santander, con 4 casos cada uno; Antioquia, Cesar y Sucre, con 3 casos cada uno; Cartagena, Córdoba, Cundinamarca, Huila, Magdalena, Norte de Santander y Exterior, con 2 casos cada uno; Amazonas, Arauca, Buenaventura, Casanare, La Guajira y Valle del Cauca, con 1 caso cada uno. Se han descartado 87 casos y se encuentran en estudio 38 muertes procedentes de: Huila y Sucre, con 4 casos; Casanare, Magdalena y Valle del Cauca, con 3 casos cada uno; Barranquilla, Bolívar, Cartagena, Cundinamarca Meta, Tolima, con 2 casos cada uno; Arauca, Caquetá, Cesar, Chocó, La Guajira, Quindío, Risaralda, Santa Marta y Vaupés, con 1 caso cada uno.

\section{Metodología}

Se realizó un informe descriptivo de los casos notificados durante las semanas epidemiológicas 01 a 40 de 2019, teniendo en cuenta las variables de tiempo, persona y lugar contenidas en la ficha de datos básicos y complementarios. Los indicadores se presentan en distribuciones de frecuencias en figuras y tablas.

El canal endémico nacional y el análisis de comportamiento epidemiológico por entidad territorial se realizó con la metodología de medias geométricas (Marcelo Bortman), estableciendo los siguientes límites de control: por debajo de lo esperado, número de casos menor al límite inferior IC95\%; dentro de lo esperado, número de casos entre el límite inferior y la media geométrica IC95\%; en alerta, número de casos entre la media geométrica y el límite superior IC $95 \%$, e incremento por encima de lo esperado, número de casos por encima del límite superior IC95\%.

En el canal endémico no se grafica la semana epidemiológica 40 dado que, el periodo de incubación del virus de dengue es de 3 a 14 días, por lo tanto, los casos de esa semana se reflejarán plenamente en la siguiente semana.

\section{Malaria}

En la semana epidemiológica 40 de 2019 se notificaron 1334 casos de malaria. A la fecha se han reportado 63704 , de los que, 62619 son de malaria no complicada y 1085 de malaria complicada. Predomina la infección por Plasmodium falciparum (P. falciparum) con 51,1 \% (32569 casos), seguido de Plasmodium vivax ( $P$. vivax) con $47,7 \%$ (30 391 casos), infección mixta con $1,2 \%$ ( 743 casos) y 1 caso por Plasmodium malarie (P. malarie) (Figura 22).

Figura 22. Casos notificados de malaria según especie parasitaria , Colombia, semanas epidemiológicas 01 a 38 de 2019

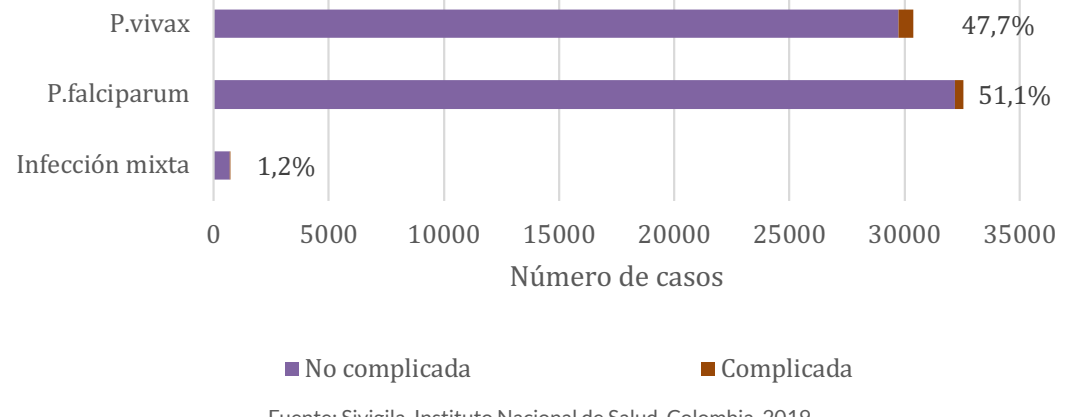

Fuente: Sivigila, Instituto Nacional de Salud, Colombia, 2019
Tema central

Situación Nal.

Mortalidad

Trazadores

Brotes

Sarampión

Tablas 


\section{Malaria no complicada}

Por procedencia, Chocó, Nariño, Córdoba, y Antioquia aportaron el $75,3 \%$ de los casos de malaria no complicada. El departamento con mayor registro fue Chocó, con el 33,6\% de los casos notificados (Tabla 12).

Tabla 12. Casos notificados de malaria no complicada por entidad territorial de procedencia. Colombia, semanas epidemiológicas 01 a 40 de 2019

\begin{tabular}{|c|c|c|c|c|c|c|}
\hline Entidad territorial & Infección mixta & P. falciparum & P. malarie & P. vivax & $\mathrm{n}$ & $\%$ \\
\hline Chocó & 380 & 12945 & 0 & 7734 & 21059 & 33,60 \\
\hline Nariño & 29 & 11913 & 0 & 709 & 12651 & 20,20 \\
\hline Córdoba & 43 & 1368 & 0 & 6220 & 7631 & 12,20 \\
\hline Antioquia & 80 & 1129 & 0 & 4613 & 5822 & 9,30 \\
\hline Norte de Santander & 2 & 5 & 0 & 3063 & 3070 & 4,90 \\
\hline Cauca & 2 & 2208 & 0 & 66 & 2276 & 3,60 \\
\hline Guainía & 13 & 140 & 0 & 1345 & 1498 & 2,40 \\
\hline Bolívar & 87 & 343 & 0 & 989 & 1419 & 2,30 \\
\hline Amazonas & 8 & 116 & 0 & 1193 & 1317 & 2,10 \\
\hline Guaviare & 4 & 561 & 0 & 656 & 1221 & 1,90 \\
\hline Buenaventura & 5 & 907 & 0 & 199 & 1111 & 1,80 \\
\hline Vichada & 3 & 53 & 0 & 459 & 515 & 0,80 \\
\hline Risaralda & 5 & 11 & 0 & 425 & 441 & 0,70 \\
\hline Meta & 1 & 130 & 0 & 245 & 376 & 0,60 \\
\hline Vaupés & 0 & 110 & 0 & 56 & 166 & 0,30 \\
\hline Valle del Cauca & 5 & 34 & 0 & 50 & 89 & 0,10 \\
\hline Caquetá & 0 & 13 & 0 & 46 & 59 & 0,10 \\
\hline Arauca & 1 & 2 & 0 & 55 & 58 & 0,10 \\
\hline Sucre & 1 & 3 & 0 & 25 & 29 & 0,00 \\
\hline Santander & 0 & 2 & 0 & 19 & 21 & 0,03 \\
\hline Cesar & 0 & 3 & 0 & 18 & 21 & 0,03 \\
\hline Santa Marta & 0 & 1 & 0 & 14 & 15 & 0,02 \\
\hline La Guajira & 1 & 1 & 0 & 13 & 15 & 0,02 \\
\hline Putumayo & 0 & 4 & 0 & 10 & 14 & 0,02 \\
\hline Atlántico & 0 & 2 & 0 & 9 & 11 & 0,02 \\
\hline Cartagena & 0 & 2 & 0 & 8 & 10 & 0,02 \\
\hline Casanare & 0 & 4 & 0 & 4 & 8 & 0,01 \\
\hline Magdalena & 0 & 1 & 0 & 6 & 7 & 0,01 \\
\hline Barranquilla & 0 & 1 & 0 & 4 & 5 & 0,01 \\
\hline Quindío & 0 & 1 & 0 & 4 & 5 & 0,01 \\
\hline Huila & 1 & 0 & 0 & 3 & 4 & 0,01 \\
\hline Caldas & 0 & 0 & 0 & 4 & 4 & 0,01 \\
\hline Desconocido & 1 & 5 & 0 & 29 & 35 & 0,06 \\
\hline Exterior & 30 & 169 & 1 & 1436 & 1636 & 2,72 \\
\hline Total & 702 & 32187 & 1 & 29729 & 62619 & 100 \\
\hline
\end{tabular}

Fuente: Sivigila, Instituto Nacional de Salud, Colombia, 2019

A semana epidemiológica 40 de 2019 el índice parasitario anual (IPA) de malaria fue de 7,93 casos por cada 1000 habitantes en riesgo (población del área rural); hubo predominio de infección por
P. falciparum con un índice anual (IFA) de 4,06 casos por cada 1000 habitantes en riesgo, seguido de P. vivax, con un índice anual (IVA) 3,78 casos por cada 1000 habitantes en riesgo. El municipio Vigía del Fuerte (Antioquia) presentó el IPA municipal más alto con 236,9 casos por cada 1000 habitantes en riesgo (Tabla 13).

Tabla 13. Municipios en mayor riesgo epidemiológico para malaria en Colombia, semanas epidemiológicas 01 a 38 de 2019

\begin{tabular}{|c|c|c|c|c|c|}
\hline Municipio & Departamento & IPA & IVA & \multicolumn{2}{|c|}{ IFA } \\
\hline Vigía del Fuerte & Antioquia & 236,9 & & 103,5 & 118,3 \\
\hline Bagadó & Chocó & 215,1 & & 162,3 & 50,3 \\
\hline Bajo Baudó & Chocó & 124,5 & & 55,7 & 66,9 \\
\hline La Pedrera & Amazonas & 113,2 & & 111,7 & 1,5 \\
\hline Río Quito & Chocó & 81,8 & & 11,0 & 69,5 \\
\hline Tadó & Chocó & 79,5 & & 24,9 & 54,3 \\
\hline Roberto Payán & Nariño & 73,6 & & 3,5 & 70,1 \\
\hline Tibú & Norte de Santander & 73,3 & & 73,2 & 0,1 \\
\hline Murindó & Antioquia & 73,3 & & 70,5 & 2,8 \\
\hline Olaya Herrera & Nariño & 67,5 & & 5,1 & 62,4 \\
\hline Inírida & Guainía & 67,3 & & 60,4 & 6,2 \\
\hline Tarapacá & Amazonas & 67,2 & & 51,5 & 15,3 \\
\hline Barbacoas & Nariño & 62,9 & & 3,4 & 59,4 \\
\hline Lloró & Chocó & 62,9 & & 12,0 & 48,2 \\
\hline Alto Baudo & Chocó & 58,0 & & 24,5 & 32,0 \\
\hline Montecristo & Bolívar & 55,2 & & 43,8 & 8,9 \\
\hline Atrato & Chocó & 51,4 & & 5,7 & 44,9 \\
\hline Medio Baudó & Chocó & 48,0 & & 31,2 & 13,9 \\
\hline
\end{tabular}

Fuente: Sivigila, Instituto Nacional de Salud, Colombia, 2019 IPA: Número de casos/población a riesgo (área rural)* 1000

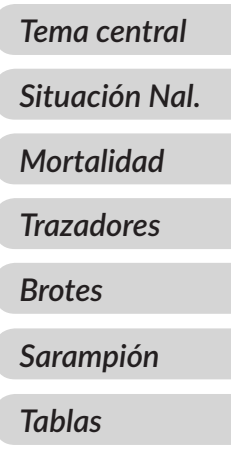




\section{BES}

Malaria Complicada

Se notificaron 1085 casos de malaria complicada procedentes de 30 entidades territoriales y 95 casos procedentes del exterior (Figura 19).

Figura 19. Casos notificados de malaria complicada por entidad territorial de procedencia, Colombia, semanas epidemiológicas 01 a 40 de 2019

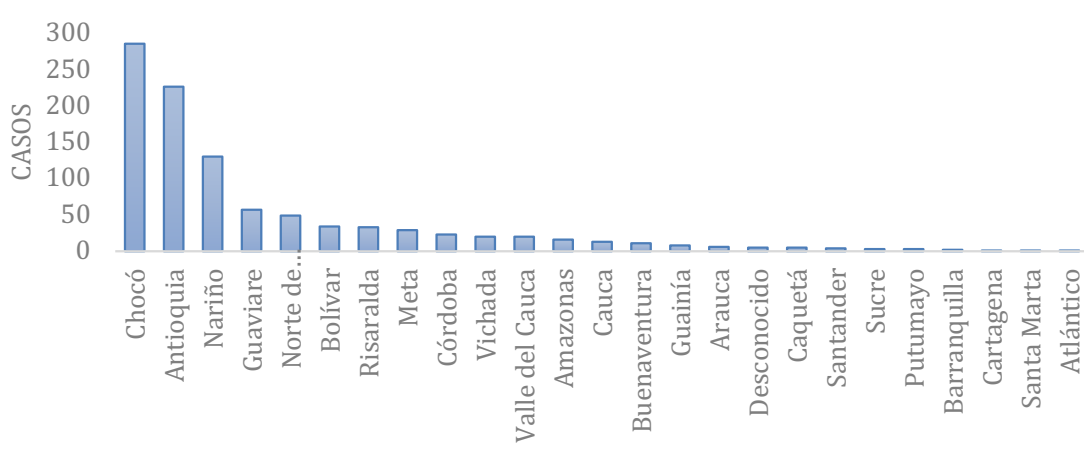

ENTIDAD TERRITORIAL DE PROCEDENCIA

Fuente: Sivigila, Instituto Nacional de Salud, Colombia, 2019 Nota: No se presentaron casos de otros departamentos o distritos

De los casos de malaria complicada, 607 casos (55,9\%) correspondieron a hombres. Hubo 143 casos (13,2\%) pertenecientes al grupo de edad de 20 a 24 años, además de 256 (23,6\%) afrocolombianos y $220(20,3 \%)$ indígenas. Por lugar de procedencia, 439 casos $(40,5$ $\%)$ provienen de cabecera municipal; por régimen de afiliación, 643 $(59,3 \%)$ son del régimen subsidiado.

De los 986 casos notificados de malaria complicada, el 72 \% (778 casos) presentaron complicaciones hematológicas, el $18 \%$ (195 casos) hepáticas, el $6 \%$ (69 casos) renal, $3 \%$ (35 casos) pulmonar y el $14 \%$ (157 casos) otras complicaciones (Figura 20).
Figura 20. Tipo de complicaciones de malaria en Colombia, semanas epidemiológicas 01 a 40 de 2019

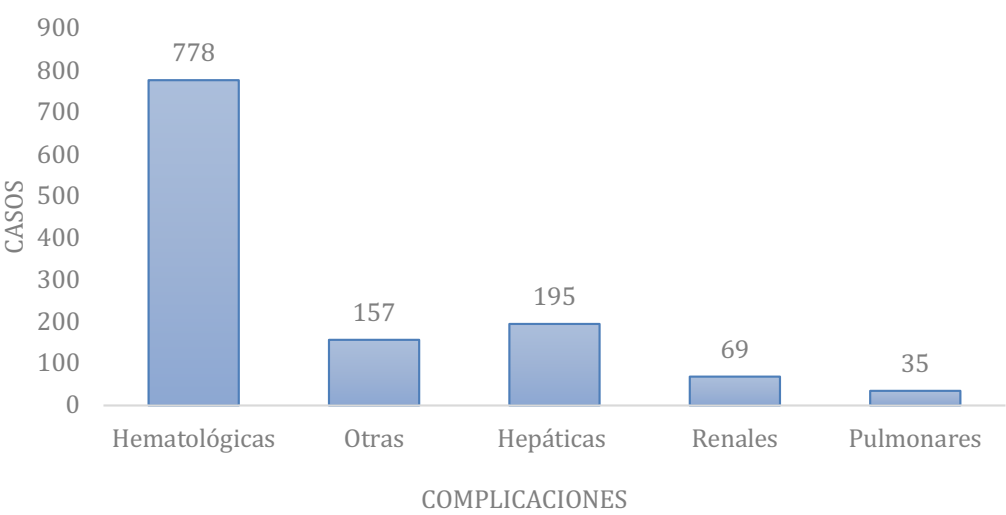

Fuente: Sivigila, Instituto Nacional de Salud, Colombia 2019

De acuerdo con la situación epidemiológica presentada en la semana 40 por departamento de procedencia, 3 departamentos están por encima del número esperado de casos y 1 departamento está en situación de alerta para malaria (Tabla 14).

Tabla 14. Distribución de entidades territoriales según el comportamiento epidemiológico de malaria, Colombia, semanas epidemiológicas 01 a 40 de 2019

\begin{tabular}{llll}
\hline Comportamiento epidemiológico & Departamentos & & \\
\cline { 1 - 3 } Menor al comportamiento histórico & Chocó & Valle del Cauca & \\
& Cundinamarca & Vichada & \\
& Guaviare & & \\
En el comportamiento histórico & Amazonas & Casanare & Magdalena \\
& Antioquia & Cesar & Nariño \\
& Arauca & Córdoba & Putumayo \\
& Bolívar & Guainía & Risaralda \\
& Caldas & Huila & Santander \\
& & Vaupés & Sucre \\
Situación de alerta & Caquetá & & \\
Mayor al comportamiento histórico & Cauca & & \\
& Meta & & \\
& Norte de Santander & & \\
& Fuente: Sivigia, Instituto Nacional de Salud,Colombia 2019 &
\end{tabular}

\section{Tema central \\ Situación Nal.}

Mortalidad

Trazadores

Brotes

Sarampión

Tablas 


\section{Casos registrados como procedentes del exterior}

Hasta la semana epidemiológica 40 de 2019 se han notificado 1731 casos procedentes del exterior, el $96,3 \%$ son procedentes de Venezuela. Se registraron 1636 casos de malaria no complicada y 95 de malaria complicada; 1507 casos con infección por $P$. vivax; 187 con infección por $P$. falciparum, 36 con infección mixta y 1 con infección por $P$. malarie (Tabla 15).

Tabla 15. Casos procedentes de exterior notificados de malaria en Colombia, semanas epidemiológicas 01 a 40 de 2019

\begin{tabular}{lrrrrrr} 
País de procedencia & Infección mixta P. falciparum P. malarie & P. vivax & \multicolumn{1}{c}{$\mathrm{n}$} & \multicolumn{1}{c}{$\%$} \\
\hline Venezuela & 33 & 170 & 0 & 1463 & 1666 & 96,2 \\
Uganda & 0 & 1 & 0 & 0 & 1 & 0,1 \\
República del Congo & 0 & 1 & 1 & 0 & 2 & 0,1 \\
Perú & 0 & 0 & 0 & 18 & 18 & 1,0 \\
Nigeria & 0 & 1 & 0 & 0 & 1 & 0,1 \\
Macedonia & 0 & 1 & 0 & 0 & 1 & 0,1 \\
India & 0 & 1 & 0 & 0 & 1 & 0,1 \\
Guayana Francesa & 0 & 0 & 0 & 1 & 1 & 0,1 \\
Ecuador & 0 & 1 & 0 & 1 & 2 & 0,1 \\
Costa de Marfil & 0 & 1 & 0 & 0 & 1 & 0,1 \\
Desconocido & 1 & 6 & 0 & 12 & 19 & 1,1 \\
\hline Camerún & 0 & 2 & 0 & 0 & 2 & 0,1 \\
\hline Brasil & 1 & 2 & 0 & 12 & 15 & 0,9 \\
\hline Angola & 1 & 0 & 0 & 0 & 1 & 0,1 \\
\hline Total & 36 & 187 & 1 & 1507 & 1731 & 100 \\
\hline
\end{tabular}

Fuente: Sivigila, Instituto Nacional de Salud, Colombia 2019

\section{Metodología}

Se realizó un análisis descriptivo con corte a semana epidemiológica 40 de 2019, con información que incluye como mínimo: descripción de los casos en tiempo, lugar y persona, análisis de tendencia, descripción y análisis de indicadores para la vigilancia.

La población para la construcción de los indicadores corresponde a la proyección de población 2005 - 2020 DANE y de las poblaciones por municipio en situación de riesgo vigentes para cada año, consolidadas por el programa de enfermedades endemoepidémicas del Ministerio de Salud y Protección Social (MSPS)

Se calcularon parasitarios anuales (IPA), con la información de los casos notificados al Sivigila según especie parasitaria, P. vivax (IVA) o P. falciparum (IFA). Como numerador: número de casos confirmados de malaria (para el caso de IVA e IFA la especie parasitaria) yenominador: población ariesgo estimada para malariapropuesta por elMinisteriode Saludy Protección Social, con baseenlacirculacióndelvectory los por micipiosubi or debajo de los $1.500 \mathrm{msnm}$. Se debe tener en cuenta los parámetros: < 1 Riesgo bajo, 1- 9 , Riesgo medio $y>10$ Riesgo alto.

\section{BROTES Y SITUACIONES DE EMERGENCIA EN SALUD PÚBLICA}

\section{ALERTAS INTERNACIONALES}

\section{Enfermedad por el virus del Ébola (EVE) - República Democrá- tica del Congo, fecha de publicación 08 de octubre de 2019}

Entre el 30 de septiembre al 6 de octubre, se confirmaron 14 casos nuevos de EVE en la República Democrática del Congo (RDC). Aunque la disminución en el número de casos nuevos es alentadora, las recientes fluctuaciones en el número de casos por semanas deben interpretarse con precaución, ya que la notificación de casos depende del nivel de acceso y seguridad. En la última semana se registraron graves incidentes de seguridad en el área de salud de Lwemba, zona de salud de Mandima, por lo cual las actividades de respuesta siguen siendo limitadas.

Hasta el 08 de octubre de 2019, se han notificado un total de 3207 casos de EVE, incluidos 3093 casos confirmados y 114 casos probables, de los cuales 2144 fallecieron (índice de letalidad general del 67\%). Del total de casos confirmados y probables, 59\% (1 797) son mujeres, 31\% (909) niños menores de 18 años y 5\% (162) trabajadores de la salud. Las provincias más afectadas continúan siendo North Kivu, Ituri y South Kivu. Los casos se han concentrado con mayor proporción en las zonas de salud de Beni, Mabalako, Mandima y Mambasa.

Hasta el 04 de octubre de 2019, se estima que 1000 personas han sobrevivido a EVE en este brote. Muchos sobrevivientes están trabajando en la respuesta y son una parte importante del cuidado de enfermos y del acceso a las comunidades.

Los niveles de riesgo nacionales y regionales continúan siendo muy altos, aunque la Organización Mundial de la Salud (OMS) no aconseja cualquier restricción de viaje o comercio con la República Democrática del Congo, ni requerimiento de vacunación a través de fronteras o emisión de visas. Los viajeros deben consultar al médico 
antes de viajar y tener una buena higiene.

Fuente: Organización Mundial de la Salud, Noticias de brotes de enfermedades: Actualización 10 de octubre de 2019. Fecha de consulta 10 de octubre de 2019.

\section{Actualización temporada de transmisión del virus del Nilo Occidental en Europa, fecha de publicación 04 de octubre de 2019}

Entre el 27 de septiembre y el 3 de octubre de 2019, los Estados miembros de la Unión Europea (UE) notificaron 29 casos de virus del Niño Occidental en humanos: Italia (12), Hungría (8), Grecia (7), Alemania (1) y Francia (1). En la misma semana, Alemania, Grecia, Francia, Hungría, Italia y España informaron 15 brotes entre équidos.

Desde el comienzo de la temporada de transmisión de 2019 y hasta el 3 de octubre de 2019, los Estados miembros de la UE y los países vecinos de la UE informaron 404 infecciones humanas. Hasta la fecha, se han informado 39 muertes debidas a la infección por el virus del Nilo Occidental: Grecia (27), Rumania (5), Italia (4), Chipre (1), Macedonia del Norte (1) y Serbia (1).

Fuente: Centro europeo para la prevención y el control de enfermedades. Actualización 04 de octubre de 2019. Fecha de consulta 09 de octubre de 2019.

\section{Actualización, fiebre amarilla en Nigeria, fecha de publica- ción 08 de octubre de 2019}

Del 29 de agosto al 22 de septiembre de 2019, Nigeria notificó un brote de fiebre amarilla procedente de la reserva de caza Yankari de Alkaleri LGA, estado de Bauchi. Según el Centro de Control de Enfermedades de Nigeria (NCDC), se han reportado 231 casos sospechosos en cuatro estados, incluidos Bauchi (110), Borno (109), Gombe (10) y Kano (2), de los cuales ha habido 13 casos positivos a través de pruebas de IgM y 24 casos positivos por reacción en cadena de la polimerasa de transcriptasa inversa (RT-PCR). De 24 casos confirmados por RT-PCR ( 20 casos en Bauchi, tres en Gombe y uno en el estado de Kano), se informaron seis muertes, todas de Alkaleri LGA, estado de Bauchi, lo que resultó en una tasa de letalidad del $25 \%$ entre los casos confirmados. Se desconoce el historial de vacunación de los 231 casos sospechosos de fiebre amarilla.

Esta es la primera vez que se informan casos en relación con esta área desde que comenzó el brote en Nigeria en septiembre de 2017. Este brote es único en la amplia distribución geográfica de los casos, la mayoría con vínculos a través de viajes, trabajo o residencia en o cerca a, la reserva de caza Yankari, que es una zona ecológica altamente propensa a la circulación del virus de la fiebre amarilla (vectores, reservorio).

La OMS recomienda la vacunación contra la fiebre amarilla para todos los viajeros internacionales de más de nueve meses que van a Nigeria, ya que hay evidencia de transmisión persistente o periódica del virus de la fiebre amarilla. Nigeria también requiere un certificado de vacunación contra la fiebre amarilla para los viajeros mayores de un año que llegan de países con riesgo de transmisión de la fiebre amarilla.

Fuente: Organización Mundial de la Salud, Noticias de brotes de enfermedades: Actualización 08 de octubre de 2019. Fecha de consulta 09 de octubre de 2019.
Tema central

Situación Nal.

Mortalidad

Trazadores

Brotes

Sarampión

Tablas 


\section{ALERTAS NACIONALES}

\section{Probable brote de Infecciones Asociadas a la Atención en Salud (IAAS), Santa Marta - Magdalena}

En lo corrido del año se han obtenido tres cultivos positivos para un microorganismo en pacientes que se encontraban en unidad de cuidados intensivos (UCI) en Santa Marta. Los casos ocurrieron en la semana epidemiológica 17, 29 y 37 respectivamente. Como factor de riesgo se identifica como fuente predominante la presencia de catéter venoso central, predominio de internación en unidad de cuidado crítico, presencia de catéter urinario y estancia prolongada igual o mayor a 7 días en UCl. La institución de salud ha intensificado acciones de limpieza y desinfección.

Fuente: Secretaría de Salud Departamental Magdalena, informe de investigación de brote de IAAS, octubre 2019.

\section{Seguimiento brote de enfermedad transmitida por alimen- tos (ETA), albergue, Medellín, Antioquia}

El 05 de septiembre de 2019 se presentó un brote de ETA en un albergue donde asisten personas en proceso de desintoxicación en la ciudad de Medellín, con una tasa de ataque del $24 \%$, enfermos: 19 , expuestos: 74 . Se tomaron muestras de alimentos las cuales fueron procesadas por INVIMA y se obtiene como resultado presencia de Listeria monocytogenes en la papa. Las personas afectadas fueron tratadas ambulatoriamente, sin complicaciones.

Fuente: Secretaría Seccional de Salud y Protección Social de Antioquia, informe de investigación de brote de ETA, octubre 2019

\section{Seguimiento a brote de intoxicación por sustancia química en estudio, municipio de Dagua, Valle del Cauca}

El 3 de octubre se presenta brote de intoxicación con fuente desconocida en una institución educativa del municipio de Dagua, Valle del Cauca. A la fecha se tienen 37 casos en estudio, de los cuales 31 casos corresponden a casos primarios (estudiantes del colegio) y seis a casos secundarios. Las personas hospitalizadas presentaron evolución clínica y fueron dados de alta. Los síntomas manifestados fueron disnea, taquicardia, parestesias y calambres en extremidades superiores e inferiores. Se está investigando la posible sustancia implicada y la vía de exposición. Ante la situación presentada, se activaron organismos locales de respuesta y equipo de respuesta inmediata departamental y nacional en articulación con Centro Regulador de Urgencias, Unidad Ejecutora de Saneamiento, Bomberos y Secretaría de Salud Municipal de Cali. Desde la secretaria de salud departamental se han establecido diferentes estrategias de comunicación del riesgo como comunicados en canal regional, comunicados por parte de las instituciones de salud de Cali y ubicación de las personas que enviaron mensajes de audio por redes sociales, aclarando la situación, informando que la situación ya está controlada.

Fuente: Secretaría de Salud Departamental Valle del Cauca, informe de investigación de brote de intoxicación Dagua, octubre 2019. 


\section{SARAMPIÓN}

La identificación de la fuente de infección en los casos confirmados de sarampión permite evaluar la reaparición de la transmisión endémica del virus en el país. La Organización Panamericana de la Salud (OPS) y la Organización Mundial de la Salud (OMS), clasifican la fuente de infección en tres categorías:

Caso importado de sarampión: es un caso confirmado que, según las pruebas epidemiológicas o virológicas, estuvo expuesto al virus fuera de Colombia durante los siete a 21 días anteriores al inicio del exantema. En el caso de la rubéola, este plazo es de 12 a 23 días.

Caso relacionado con importación: es un caso confirmado que según las pruebas epidemiológicas o virológicas, estuvo expuesto localmente al virus y forma parte de una cadena de transmisión iniciada por un caso importado.

Caso con fuente de infección desconocida: es un caso confirmado en el que no se pudo detectar la fuente de infección.

Desde 2018 y hasta el 10 de octubre de 2019, el Instituto Nacional de Salud (INS) ha confirmado 416 casos de sarampión. En 2018 se confirmaron 208 casos (58 importados, 140 relacionados con la importación y 10 de fuente infección desconocida).

Hasta la semana epidemiológica 40 de 2019 han ingresado 3782 casos sospechosos, se han descartado 3119 , permanecen en estudio 455 y se han confirmado 208.

De los 208 casos confirmados en 2019, el 31 \% (65) es importado; el 61 \% (126) corresponde a casos relacionados con la importación así: 47 en personas procedentes de Venezuela y 79 en colombianos; para los casos restantes, el 8 \% (17) se encuentran con fuente de infección en investigación: cinco de transmisión en personas que proceden de Venezuela y 12 en colombianos (Tabla 16).
Tabla 16. Clasificación casos sospechosos de sarampión y rubéola según procedencia, Colombia, 2018 a semana epidemiológica 40 de 2019

\begin{tabular}{lrrrrr} 
& 2018 & 2019 & & & \\
\cline { 2 - 5 } Procedencia & Confirmado & Confirmado & Descartado & En estudio & 2019 \\
& 1 & 0 & 123 & 41 & 164
\end{tabular}

\begin{tabular}{|c|c|c|c|c|c|}
\hline Antioquia & 1 & 0 & 123 & 41 & 164 \\
\hline Amazonas & 0 & 0 & 13 & 3 & 16 \\
\hline Arauca & 1 & 0 & 2 & 0 & 2 \\
\hline $\begin{array}{l}\text { Archipiélago de San Andrés, } \\
\text { Providencia y Santa Catalina }\end{array}$ & 0 & 0 & 5 & 0 & 5 \\
\hline Atlántico & 2 & 2 & 55 & 16 & 73 \\
\hline Barranquilla & 36 & 4 & 225 & 73 & 302 \\
\hline Bogotá, D.C. & 4 & 12 & 1987 & 170 & 2169 \\
\hline Bolívar & 12 & 0 & 15 & 4 & 19 \\
\hline Boyacá & 0 & 0 & 16 & 0 & 16 \\
\hline Buenaventura & 0 & 0 & 0 & 0 & 0 \\
\hline Caldas & 0 & 0 & 12 & 2 & 14 \\
\hline Caquetá & 0 & 0 & 9 & 3 & 12 \\
\hline Cartagena de Indias & 67 & 3 & 74 & 14 & 91 \\
\hline Casanare & 0 & 0 & 3 & 1 & 4 \\
\hline Cauca & 0 & 0 & 0 & 2 & 2 \\
\hline Cesar & 1 & 0 & 12 & 6 & 18 \\
\hline Chocó & 0 & 0 & 0 & 3 & 3 \\
\hline Córdoba & 0 & 1 & 5 & 3 & 9 \\
\hline Cundinamarca & 1 & 0 & 198 & 26 & 224 \\
\hline Exterior & 57 & 57 & 61 & 3 & 121 \\
\hline Guainía & 0 & 0 & 1 & 2 & 3 \\
\hline Guaviare & 0 & 0 & 2 & 0 & 2 \\
\hline Huila & 0 & 0 & 6 & 1 & 7 \\
\hline La Guajira* & 6 & 82 & 63 & 1 & 146 \\
\hline Magdalena & 0 & 0 & 5 & 0 & 5 \\
\hline Meta & 0 & 0 & 7 & 1 & 8 \\
\hline Nariño & 0 & 0 & 14 & 7 & 21 \\
\hline Norte de Santander* & 15 & 46 & 93 & 16 & 155 \\
\hline Putumayo & 0 & 0 & 4 & 1 & 5 \\
\hline Quindío & 0 & 0 & 5 & 3 & 8 \\
\hline Risaralda & 0 & 0 & 19 & 2 & 21 \\
\hline Santa Marta & 1 & 0 & 6 & 3 & 9 \\
\hline Santander & 0 & 0 & 23 & 13 & 36 \\
\hline Sucre & 4 & 1 & 15 & 18 & 34 \\
\hline Tolima & 0 & 0 & 18 & 5 & 23 \\
\hline Valle del Cauca & 0 & 0 & 19 & 11 & 30 \\
\hline Vaupés & 0 & 0 & 0 & 0 & 0 \\
\hline Vichada & 0 & 0 & 4 & 1 & 5 \\
\hline Total & 208 & 208 & 3119 & 455 & 3782 \\
\hline
\end{tabular}

Departamentos y distritos que presentaron casos confirmados durante las últimas cuatro semanas.

Fuente: Grupo Inmunoprevenibles Grupo de Gestión del Riesgo y Respuesta Inmediata - Dirección de Vigilancia y Análisis del Riesgo en Salud Pública. Grupo de Virología - Red Nacional de Laboratorios.
Tema centra

Situación Nal.

Mortalidad

Trazadores

Brotes

Sarampión

Tablas 
Del total de casos confirmados en el país, el $29 \%$ (122) son casos importados, 57 casos en 2018 y 65 en 2019. La Guajira y Norte de Santander son los departamentos que más casos han notificado (Tabla 17).

Tabla 17. Casos importados de sarampión según entidad territorial notificadora, Colombia, 2018 a semana epidemiológica 40 de 2019

$\begin{array}{lccc}\text { Departamento notificador } & 2018 & 2019 & \text { Total general } \\ \text { Antioquia } & 4 & 0 & 4 \\ \text { Barranquilla } & 2 & 0 & 2 \\ \text { Bogotá, D.C. } & 6 & 3 & 9 \\ \text { Bolívar } & 2 & 0 & 2 \\ \text { Cartagena de Indias } & 6 & 0 & 6 \\ \text { Cauca } & 1 & 0 & 1 \\ \text { Cesar } & 2 & 1 & 3 \\ \text { Córdoba } & 0 & 1 & 1 \\ \text { Cundinamarca } & 2 & 1 & 3 \\ \text { La Guajira* } & 2 & 42 & 44 \\ \text { Magdalena } & 1 & 0 & 1 \\ \text { Norte de Santander* } & 22 & 17 & 39 \\ \text { Risaralda } & 1 & 0 & 1 \\ \text { Santa Marta } & 1 & 0 & 1 \\ \text { Santander } & 1 & 0 & 1 \\ \text { Sucre } & 4 & 0 & 4 \\ \text { Total } & 57 & 65 & 122\end{array}$

*Departamentos y distritos que presentaron casos confirmados durante las últimas 4 semanas. Fuente: Grupo Inmunoprevenibles, Grupo de Gestión del Riesgo y Respuesta Inmediata - Dirección de Vigilancia

y Análisis del Riesgo en Salud Pública. Grupo de Virología - Red Nacional de Laboratorios

Entidades territoriales con brote cerrado: hasta la semana epidemiológica 40 de 2019, Cartagena completa 47 semanas sin presentar casos nuevos, Bogotá 38 semanas y Barranquilla 28 semanas. 
BES

Boletín Epidemiológico Semanal

\section{TABLAS DE MANDO NACIONAL}

Comportamiento de la notificación por departamento a semana 40

\begin{tabular}{|c|c|c|c|c|c|c|c|c|c|c|c|c|c|c|c|c|c|c|c|c|c|}
\hline \multirow[b]{2}{*}{ Departamento } & \multicolumn{3}{|c|}{ Accidente ofidico } & \multicolumn{3}{|c|}{$\begin{array}{c}\text { Agresiones por animales } \\
\text { potencialmente transmisores de } \\
\text { rabia }\end{array}$} & \multicolumn{3}{|c|}{ Dengue } & \multicolumn{3}{|c|}{ ESAVI grave } & \multicolumn{3}{|c|}{ Intento de suicidio } & \multicolumn{3}{|c|}{ Intoxicaciones por medicamentos } & \multicolumn{3}{|c|}{ Intoxicaciones por plaguicidas } \\
\hline & 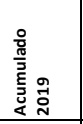 & 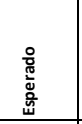 & 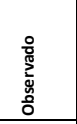 & 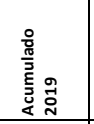 & 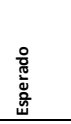 & 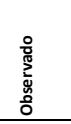 & 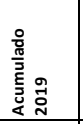 & 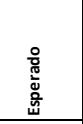 & 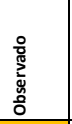 & 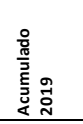 & 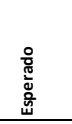 & 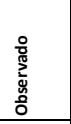 & 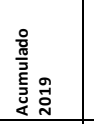 & $\begin{array}{l}\text { 윰 } \\
\text { 总 } \\
\text { 总 } \\
\end{array}$ & 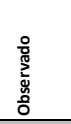 & 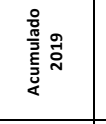 & 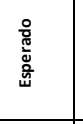 & $\begin{array}{l}\text { 윰 } \\
\text { ᄅ्रू } \\
\text { ồ }\end{array}$ & 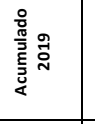 & 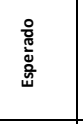 & 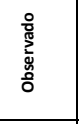 \\
\hline \begin{tabular}{|l|} 
Amazonas \\
Antioquiai
\end{tabular} & \begin{tabular}{r|}
34 \\
605 \\
\end{tabular} & \begin{tabular}{|r|}
13 \\
13
\end{tabular} & \begin{tabular}{r|}
2 \\
14 \\
\end{tabular} & \begin{tabular}{|r|}
230 \\
12.010 \\
\end{tabular} & $\begin{array}{r}5 \\
221\end{array}$ & $\begin{array}{r}7 \\
247\end{array}$ & \begin{tabular}{|l|}
1.024 \\
4.820 \\
\end{tabular} & $\begin{array}{r}19 \\
412\end{array}$ & \begin{tabular}{r|}
245 \\
482
\end{tabular} & $\begin{array}{r}\mathrm{N}^{2} \\
33\end{array}$ & $\begin{array}{l} \\
\\
\end{array}$ & 0 & \begin{tabular}{r|}
49 \\
4.134 \\
\end{tabular} & 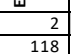 & $\begin{array}{r}0 \\
107\end{array}$ & \begin{tabular}{r|}
2 \\
515
\end{tabular} & $\frac{0}{10}$ & $\frac{0}{7}$ & \begin{tabular}{r|r}
4 \\
404
\end{tabular} & \begin{tabular}{l|}
0 \\
8
\end{tabular} & $\frac{0}{15}$ \\
\hline 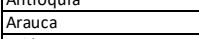 & $\begin{array}{c}803 \\
88\end{array}$ & $\frac{13}{3}$ & $\frac{14}{3}$ & 440 & $\frac{221}{12}$ & $\frac{247}{12}$ & $\begin{array}{ll}4.8206 \\
1.896 \\
\end{array}$ & $\frac{412}{39}$ & $\frac{402}{80}$ & $\frac{33}{1}$ & $\frac{3}{1}$ & 0 & $\begin{array}{r}4.154 \\
163 \\
\end{array}$ & 3 & $\frac{101}{4}$ & $\begin{array}{c}313 \\
11\end{array}$ & $\frac{10}{0}$ & $\frac{1}{1}$ & $\begin{array}{ll}404 \\
52\end{array}$ & 2 & \\
\hline Atlántico & 112 & 2 & 2 & 2.292 & 43 & 43 & 1.314 & 169 & 185 & 7 & 1 & 1 & 626 & 19 & 13 & 111 & 2 & 3 & 63 & 1 & \\
\hline Barranquilla & 7 & 1 & 0 & 1.968 & 36 & 39 & 784 & 124 & 127 & 8 & 1 & 0 & 716 & 22 & 21 & 174 & 3 & 4 & 66 & 1 & \\
\hline Bogotá & 1 & 0 & 0 & 16.763 & 344 & 400 & 0 & 0 & 0 & 116 & 9 & 9 & 883 & 25 & 41 & 675 & 18 & 11 & 104 & 3 & \\
\hline \begin{tabular}{|l|l|l} 
Bolivar \\
\end{tabular} & 239 & 6 & 4 & $\begin{array}{ll}1.647 \\
\end{array}$ & 37 & 31 & 2.237 & 137 & 316 & 10 & 1 & 2 & 318 & 7 & 4 & \begin{tabular}{l|l}
75 \\
\end{tabular} & 0 & 1 & 67 & 2 & 4 \\
\hline Boyacá & 54 & 1 & 1 & 4.458 & 93 & 111 & 876 & 38 & 43 & 6 & 2 & 0 & \begin{tabular}{l|l}
637 \\
\end{tabular} & 15 & 15 & 93 & 1 & 3 & \begin{tabular}{l|l}
93 \\
\end{tabular} & 1 & 0 \\
\hline \begin{tabular}{|l|l|} 
Buenaventura \\
\end{tabular} & 21 & 1 & 0 & 87 & 2 & 0 & 70 & 12 & 4 & 0 & 0 & 0 & 42 & 3 & 1 & \begin{tabular}{l|l}
6 \\
\end{tabular} & 0 & 0 & 4 & 0 & 0 \\
\hline \begin{tabular}{|l|} 
Caldas \\
\end{tabular} & 42 & 1 & 4 & 2.699 & 55 & 73 & 473 & 33 & 75 & 3 & 2 & 0 & 889 & 29 & 32 & 85 & 2 & 0 & \begin{tabular}{l|l}
103 \\
\end{tabular} & 2 & 3 \\
\hline Caquetá & 148 & 2 & 2 & 781 & 18 & 16 & 684 & 34 & 88 & 5 & 1 & 1 & 214 & 6 & 5 & 29 & 1 & 0 & 45 & 1 & \\
\hline \begin{tabular}{|l|} 
Cartagena \\
\end{tabular} & 19 & 1 & 0 & 897 & 13 & 16 & 993 & 52 & 136 & 6 & 1 & 1 & \begin{tabular}{l|l}
431 \\
\end{tabular} & 10 & 6 & 56 & 1 & 0 & 22 & 0 & 0 \\
\hline \begin{tabular}{|l|} 
Casanare \\
\end{tabular} & 105 & 4 & 4 & 930 & 24 & 29 & 5.081 & 101 & 257 & 1 & 2 & 0 & \begin{tabular}{|l|l|}
231 \\
237
\end{tabular} & 6 & 9 & 23 & 1 & 0 & \begin{tabular}{l|l}
55 \\
120
\end{tabular} & 1 & 0 \\
\hline Cauca & 103 & 2 & 0 & 4.228 & 97 & 83 & 319 & 22 & 23 & 17 & 2 & 1 & \begin{tabular}{l|l|}
707 \\
\end{tabular} & 21 & 18 & 58 & 2 & 1 & 124 & 3 & 2 \\
\hline Cesar & 286 & 6 & 6 & 1.509 & 29 & 36 & 5.127 & 270 & 552 & 3 & 1 & 0 & \begin{tabular}{l|l|}
494 \\
94
\end{tabular} & 12 & 8 & 81 & 2 & 1 & 83 & 3 & 0 \\
\hline Choco & 190 & 3 & 2 & $\begin{array}{r}84 \\
\end{array}$ & 1 & 2 & 179 & 14 & 32 & 0 & 1 & 0 & 94 & \begin{tabular}{c|c}
4 \\
\end{tabular} & 0 & \begin{tabular}{r|r}
7 \\
07 \\
\end{tabular} & 0 & 0 & 16 & 1 & \\
\hline \begin{tabular}{|l} 
Córdoba \\
\end{tabular} & 306 & 7 & 10 & 2.878 & 49 & 41 & 3.425 & 206 & 300 & 6 & $\frac{1}{2}$ & 0 & \begin{tabular}{|l|l|}
757 \\
\end{tabular} & 17 & 14 & 97 & \begin{tabular}{l|l}
$\frac{1}{3}$ \\
\end{tabular} & $\frac{1}{4}$ & 137 & $\begin{array}{l}2 \\
3\end{array}$ & \\
\hline \begin{tabular}{|l} 
Cundinamarca \\
\end{tabular} & 63 & 1 & 2 & 9.432 & 171 & 230 & 2.776 & 164 & 231 & 23 & 2 & 2 & \begin{tabular}{l|l}
1.603 \\
21
\end{tabular} & 44 & 33 & \begin{tabular}{l|l|}
119 & \\
2
\end{tabular} & 3 & 4 & 115 & 3 & \\
\hline Guainia & 5 & 0 & 0 & 86 & 1 & 3 & 151 & 3 & 3 & 0 & 1 & 0 & 21 & 1 & 3 & \begin{tabular}{l|l}
3 & \\
5 & \\
\end{tabular} & 0 & $\frac{0}{2}$ & 1 & 0 & \\
\hline \begin{tabular}{|l|l|l} 
La Guajira \\
$a$
\end{tabular} & 106 & 2 & 6 & 1.355 & 23 & 29 & \begin{tabular}{l|l}
837 \\
512
\end{tabular} & 66 & 35 & 0 & $\frac{1}{11}$ & 0 & \begin{tabular}{l|l|}
209 \\
30
\end{tabular} & 7 & 5 & 54 & 0 & $\frac{2}{0}$ & 33 & 0 & \\
\hline \begin{tabular}{|l|} 
Guaviare \\
\end{tabular} & $\begin{array}{ll}66 \\
\end{array}$ & & 1 & 166 & 3 & $\frac{4}{78} \quad 10$ & 513 & 19 & $\begin{array}{ll}19 \\
656\end{array}$ & 2 & $\frac{1}{11}$ & 0 & 39 & 2 & 2 & $\begin{array}{ll}0 \\
8\end{array}$ & $\begin{array}{ll}0 \\
2\end{array}$ & $\frac{0}{0}$ & $\frac{10}{164}$ & $\frac{1}{2}$ & \\
\hline $\begin{array}{l}\text { Huila } \\
\text { ula }\end{array}$ & 115 & 2 & 0 & 3.028 & 63 & 78 & $\begin{array}{ll}9.158 \\
240\end{array}$ & 209 & $\begin{array}{ll}666 \\
51\end{array}$ & $\frac{27}{5}$ & $\frac{1}{11}$ & 4 & \begin{tabular}{l|l|}
756 \\
28
\end{tabular} & \begin{tabular}{l|l}
16 \\
5
\end{tabular} & $\frac{22}{41}$ & \begin{tabular}{l|l}
80 & \\
44 &
\end{tabular} & 2 & $\frac{0}{0}$ & $\frac{164}{61}$ & 2 & \\
\hline \begin{tabular}{|l} 
Magdalena \\
aga
\end{tabular} & 136 & 3 & 3 & 1.927 & $\frac{28}{553}$ & $\frac{30}{51}$ & \begin{tabular}{|l|l|}
2.440 \\
\end{tabular} & 65 & \begin{tabular}{l|l}
151 \\
768
\end{tabular} & 5 & $\frac{1}{1}$ & 0 & \begin{tabular}{l|l|l|}
268 & \\
508
\end{tabular} & 5 & 4 & \begin{tabular}{l|l}
44 \\
770
\end{tabular} & $\begin{array}{ll}0 \\
2\end{array}$ & $\frac{0}{3}$ & $\begin{array}{ll}61 \\
94 \\
\end{array}$ & $\frac{2}{6}$ & \\
\hline $\begin{array}{l}\text { Meta } \\
\text { tis. }\end{array}$ & 204 & 4 & 1 & 2.405 & 53 & 51 & \begin{tabular}{ll|l}
15.045 \\
\end{tabular} & 306 & 768 & 4 & $\frac{1}{1}$ & 1 & 570 & 13 & 14 & 70 & 2 & 3 & \begin{tabular}{l|l|}
94 \\
9
\end{tabular} & 6 & \\
\hline \begin{tabular}{|l|} 
Nariño \\
\end{tabular} & 69 & 2 & 0 & 4.555 & 78 & 105 & 442 & 19 & 38 & 16 & $\frac{1}{2}$ & 1 & \begin{tabular}{l|l|l|l|}
1.081 \\
\end{tabular} & 32 & 17 & \begin{tabular}{l|l}
119 \\
9
\end{tabular} & 3 & $\frac{1}{2}$ & \begin{tabular}{l|l}
181 \\
128
\end{tabular} & 4 & \\
\hline \begin{tabular}{|l} 
Norte Santander \\
\end{tabular} & 288 & 6 & 5 & 3.005 & 76 & 65 & 5.691 & 375 & 307 & 11 & 2 & 0 & \begin{tabular}{l|l|l}
718 \\
20
\end{tabular} & 20 & 17 & 94 & 3 & 3 & \begin{tabular}{l|l}
129 \\
50
\end{tabular} & 4 & $\frac{4}{0}$ \\
\hline \begin{tabular}{|l} 
Putumayo \\
\end{tabular} & 118 & 2 & 2 & 900 & 18 & 19 & $\begin{array}{ll}1.644 \\
250\end{array}$ & 48 & 59 & 0 & $\frac{1}{1}$ & 0 & \begin{tabular}{l|l}
280 \\
85
\end{tabular} & 9 & 8 & 13 & 1 & 0 & \begin{tabular}{l|l}
68 \\
627
\end{tabular} & 3 & $\frac{0}{2}$ \\
\hline \begin{tabular}{|l|} 
Quindio \\
Disald
\end{tabular} & 16 & 0 & 1 & 2.061 & 44 & 42 & 358 & $\frac{122}{52}$ & 77 & 16 & $\frac{1}{1}$ & 0 & 485 & 13 & 7 & \begin{tabular}{l|l}
42 \\
50
\end{tabular} & $\frac{1}{2}$ & $\frac{1}{0}$ & \begin{tabular}{l|l}
62 & -1 \\
89 &
\end{tabular} & 2 & \\
\hline Risaralda & 50 & 1 & 0 & 2.708 & $\frac{57}{4}$ & $\frac{53}{3}$ & 316 & 52 & 47 & 8 & $\frac{1}{1}$ & $\frac{0}{0}$ & \begin{tabular}{l|l}
1.016 & \\
13 &
\end{tabular} & 29 & 28 & \begin{tabular}{r|r}
150 \\
0
\end{tabular} & $\frac{2}{0}$ & $\frac{0}{0}$ & \begin{tabular}{l|l}
88 & \\
1 &
\end{tabular} & $\frac{2}{0}$ & \\
\hline 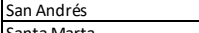 & $\begin{array}{r}0 \\
17\end{array}$ & 0 & 0 & \begin{tabular}{l|}
241 \\
943
\end{tabular} & $\frac{4}{29}$ & 3 & \begin{tabular}{r|r}
27 \\
587
\end{tabular} & $\frac{11}{43}$ & 9 & $\frac{1}{17}$ & $\frac{1}{2}$ & $\frac{0}{3}$ & \begin{tabular}{r|r|}
13 & \\
188 &
\end{tabular} & 0 & $\frac{1}{0}$ & \begin{tabular}{l|l}
0 \\
31
\end{tabular} & $\frac{0}{1}$ & $\frac{0}{0}$ & \begin{tabular}{|c|c|}
15 & \\
15 &
\end{tabular} & \begin{tabular}{l|l}
0 \\
0
\end{tabular} & $\frac{0}{0}$ \\
\hline $\begin{array}{l}\text { Santa Marta } \\
\text { Santzader }\end{array}$ & $\begin{array}{r}17 \\
197\end{array}$ & 2 & 0 & $\begin{array}{r}943 \\
4413 \\
\end{array}$ & 29 & $\begin{array}{l}16 \\
98 \\
98\end{array}$ & $\begin{array}{r}587 \\
7616\end{array}$ & $\begin{array}{r}43 \\
513 \\
\end{array}$ & $\begin{array}{r}17 \\
813 \\
\end{array}$ & $\frac{17}{5}$ & $\frac{2}{1}$ & 3 & \begin{tabular}{l|l}
188 & \\
900 &
\end{tabular} & \begin{tabular}{r|r}
6 \\
27 \\
\end{tabular} & $\begin{array}{r}0 \\
18\end{array}$ & $\begin{array}{r}31 \\
111\end{array}$ & $\frac{1}{2}$ & $\frac{0}{1}$ & \begin{tabular}{l|l}
15 & \\
97 &
\end{tabular} & \begin{tabular}{l|l}
0 \\
5
\end{tabular} & \\
\hline \begin{tabular}{|l} 
Santander \\
Surre
\end{tabular} & \begin{tabular}{l|l}
187 \\
138
\end{tabular} & 3 & 5 & $\begin{array}{l}4.413 \\
1.874\end{array}$ & 91 & 98 & $\begin{array}{l}7.616 \\
4.744 \\
\end{array}$ & 513 & 813 & 5 & 1 & $\frac{0}{0}$ & \begin{tabular}{l|l}
900 & \\
23 &
\end{tabular} & 27 & $\frac{18}{3}$ & \begin{tabular}{c|c|}
111 & \\
60 &
\end{tabular} & 2 & 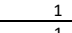 & \begin{tabular}{l|l}
97 & \\
6 &
\end{tabular} & 5 & \\
\hline $\begin{array}{l}\text { Sucre } \\
\text { Tolima }\end{array}$ & $\begin{array}{l}138 \\
121 \\
\end{array}$ & $\begin{array}{l}3 \\
1\end{array}$ & $\frac{2}{4}$ & $\begin{array}{l}1.874 \\
4.247\end{array}$ & $\begin{array}{r}37 \\
85 \\
5\end{array}$ & 32 & $\begin{array}{r}4.744 \\
10.097 \\
\end{array}$ & 203 & $\begin{array}{r}808 \\
1274 \\
\end{array}$ & $\begin{array}{r}7 \\
12\end{array}$ & $\frac{1}{1}$ & $\begin{array}{l}\frac{0}{1} \\
\end{array}$ & \begin{tabular}{r|r}
326 \\
1.151
\end{tabular} & \begin{tabular}{r|r}
73 \\
32
\end{tabular} & $\begin{array}{r}3 \\
38 \\
\end{array}$ & \begin{tabular}{l|l}
699 \\
58
\end{tabular} & $\begin{array}{l}\frac{1}{1} \\
\end{array}$ & $\frac{1}{2}$ & \begin{tabular}{r|r|}
66 & \\
110
\end{tabular} & $\begin{array}{l}2 \\
3\end{array}$ & \\
\hline Tolima & $\begin{array}{r}121 \\
49 \\
\end{array}$ & $\begin{array}{l}1 \\
1\end{array}$ & $\frac{4}{0}$ & \begin{tabular}{r|}
4.247 \\
10.209
\end{tabular} & $\begin{array}{r}85 \\
207\end{array}$ & $\frac{84}{222}$ & $\begin{array}{r}10.497 \\
3.604 \\
\end{array}$ & $\begin{array}{l}419 \\
557 \\
\end{array}$ & $\begin{array}{r}1.274 \\
691 \\
\end{array}$ & $\frac{12}{32}$ & $\frac{1}{4}$ & $\frac{1}{1}$ & \begin{tabular}{l|l}
1.151 & \\
22.37 &
\end{tabular} & 32 & 38 & $\begin{array}{r}58 \\
440\end{array}$ & $\begin{array}{l}1 \\
6\end{array}$ & $\frac{2}{10}$ & \begin{tabular}{l|l}
110 & \\
239 &
\end{tabular} & 3 & \\
\hline \begin{tabular}{|l|} 
Valle \\
Vaupés
\end{tabular} & \begin{tabular}{l|l}
49 \\
44 \\
\end{tabular} & $\begin{array}{l}1 \\
1\end{array}$ & $\frac{0}{1}$ & $\begin{array}{r}10.209 \\
103\end{array}$ & $\frac{207}{2}$ & $\frac{222}{0}$ & $\begin{array}{l}3.604 \\
163 \\
163\end{array}$ & 577 & 691 & $\frac{32}{0}$ & $\frac{4}{0}$ & $\frac{1}{0}$ & \begin{tabular}{r|r|}
2.357 & \\
6 &
\end{tabular} & $\begin{aligned} 71 \\
3\end{aligned}$ & $\frac{72}{4}$ & \begin{tabular}{r|r}
440 & \\
0 &
\end{tabular} & $\begin{array}{l}6 \\
0\end{array}$ & $\frac{10}{0}$ & \begin{tabular}{r|r}
239 & \\
2 &
\end{tabular} & \begin{tabular}{l|l}
6 \\
0
\end{tabular} & \\
\hline \begin{tabular}{|l|} 
vaupés \\
Vichada
\end{tabular} & $\begin{array}{l}44 \\
38 \\
\end{array}$ & $\begin{array}{l}1 \\
1\end{array}$ & $\frac{1}{2}$ & $\begin{array}{l}103 \\
156 \\
\end{array}$ & $\frac{2}{3}$ & $\frac{0}{0}$ & $\begin{array}{l}163 \\
352\end{array}$ & $\frac{1}{8}$ & $\begin{array}{l}31 \\
30\end{array}$ & $\frac{0}{0}$ & $\frac{0}{1}$ & $\frac{0}{0}$ & \begin{tabular}{l|l}
46 & 48 \\
18 &
\end{tabular} & 3 & $\frac{4}{0}$ & \begin{tabular}{l|l}
0 & \\
2 &
\end{tabular} & $\begin{array}{l}0 \\
0\end{array}$ & $\frac{0}{0}$ & \begin{tabular}{r|r}
2 & \\
25 &
\end{tabular} & \begin{tabular}{l|l}
0 \\
0
\end{tabular} & 0 \\
\hline \begin{tabular}{|l|l|} 
Vichada \\
Total nacional
\end{tabular} & $\begin{array}{r}30 \\
4.190 \\
\end{array}$ & \begin{tabular}{l|} 
\\
88 \\
\end{tabular} & 89 & \begin{tabular}{|l|}
107.715 \\
\end{tabular} & 2.153 & 2.350 & $\begin{array}{l}256 \\
96.263 \\
\end{array}$ & $\begin{array}{r}0.905 \\
4\end{array}$ & $\begin{array}{r}30 \\
9.019 \\
\end{array}$ & 408 & $\frac{1}{55}$ & $\frac{0}{28}$ & \begin{tabular}{r|}
18.430 \\
\end{tabular} & 657 & $\frac{0}{594}$ & \begin{tabular}{r|}
2 \\
3.597
\end{tabular} & $\begin{array}{l}0 \\
72\end{array}$ & $\frac{0}{61}$ & \begin{tabular}{r|}
25 \\
3.003
\end{tabular} & \begin{tabular}{l|l}
0 \\
76
\end{tabular} & 59 \\
\hline
\end{tabular}

$\underbrace{\text { indud }}_{\substack{\text { Instituto } \\ \text { Nacional de }}}$

\section{Tema central}

Situación Nal.

Mortalidad

Trazadores

Brotes

Sarampión

Tablas 


\begin{tabular}{|c|c|c|c|c|c|c|c|c|c|c|c|c|c|c|c|c|c|c|c|c|c|}
\hline \multirow[b]{2}{*}{ Departamento } & \multicolumn{3}{|c|}{ Intoxicaciones por metanol } & \multicolumn{3}{|c|}{ Intoxicaciones por metales } & \multicolumn{3}{|c|}{ Intoxicaciones por solventes } & \multicolumn{3}{|c|}{$\begin{array}{l}\text { Intoxicaciones por otras sustancias } \\
\text { quimicas }\end{array}$} & \multicolumn{3}{|c|}{ Intoxicaciones por gases } & \multicolumn{3}{|c|}{$\begin{array}{l}\text { Intoxicaciones por sustancias } \\
\text { psicoactivas }\end{array}$} & \multicolumn{3}{|c|}{ IRAG inusitado } \\
\hline & 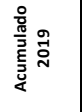 & $\begin{array}{l}\frac{0}{0} \\
\frac{\mathrm{g}}{0} \\
\frac{5}{4}\end{array}$ & $\begin{array}{l}\text { 웅 } \\
\text { 总 } \\
\text { o. }\end{array}$ & 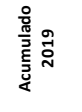 & $\begin{array}{l}\frac{\circ}{0} \\
\frac{\mathrm{g}}{\mathrm{d}} \\
\frac{\mathrm{g}}{4}\end{array}$ & 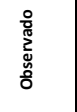 & 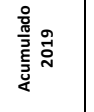 & 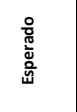 & $\begin{array}{l}\text { 울 } \\
\text { 总 } \\
\text { 岁 }\end{array}$ & 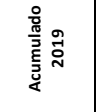 & 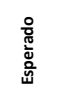 & 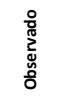 & 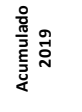 & 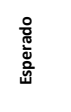 & 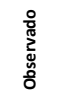 & 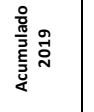 & 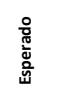 & 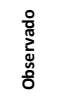 & 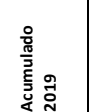 & 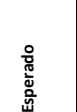 & 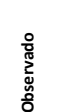 \\
\hline Amazonas & 0 & 0 & 0 & 0 & 0 & 0 & 0 & 0 & 0 & & 0 & 0 & 1 & 0 & 0 & 0 & 0 & 0 & & 0 & \\
\hline Antioquia & 25 & 0 & 0 & 19 & 0 & 0 & 45 & 3 & 0 & \begin{tabular}{ll|}
378 \\
\end{tabular} & 8 & 3 & 51 & 1 & 0 & 886 & 22 & 20 & 130 & 18 & 27 \\
\hline Arauca & 0 & 0 & 0 & 0 & 0 & 0 & 7 & 0 & 0 & 8 & 0 & 0 & 2 & 0 & 0 & 3 & 0 & 0 & 5 & 1 & 0 \\
\hline Atlántico & 5 & 0 & 0 & 1 & 1 & 0 & 32 & 0 & 2 & 94 & 2 & 3 & 16 & 0 & 0 & 67 & 3 & 0 & 11 & 2 & 0 \\
\hline Barranquilla & 11 & 0 & 0 & 1 & 0 & 0 & 31 & 2 & 1 & 104 & 3 & 0 & 15 & 0 & 0 & 208 & 5 & 1 & 14 & 3 & 0 \\
\hline Bogotá & 24 & 0 & 1 & 5 & 0 & 0 & 77 & 12 & 3 & 369 & 9 & 8 & 204 & 7 & 1 & 1.239 & 41 & 30 & 125 & 13 & \\
\hline Bolivar & 3 & 0 & 0 & 1 & 0 & 0 & 17 & 0 & 0 & \begin{tabular}{c|c|}
59 \\
\end{tabular} & 2 & 1 & 2 & 0 & 0 & 334 & 4 & 2 & 13 & 3 & \\
\hline Boyacá & 8 & 0 & 0 & 1 & 0 & 0 & 16 & 1 & 0 & 56 & 0 & 0 & 29 & 1 & 2 & 134 & 1 & 2 & 7 & 1 & \\
\hline \begin{tabular}{|l|} 
Buenaventura \\
\end{tabular} & 2 & 0 & 0 & 0 & 0 & 0 & 1 & 0 & 0 & 6 & 0 & 0 & 1 & 0 & 1 & 6 & 0 & 0 & 0 & 0 & \\
\hline \begin{tabular}{|l|l} 
Caldas \\
\end{tabular} & 11 & 0 & 0 & 1 & 0 & 0 & 23 & 2 & 0 & 42 & 2 & 1 & 12 & 0 & 0 & 251 & 11 & 2 & 13 & 1 & \\
\hline Caquetá & 0 & 0 & 0 & 1 & 0 & 0 & 4 & 0 & 0 & 26 & 1 & 2 & 1 & 0 & 0 & 24 & 1 & 1 & 4 & 2 & \\
\hline \begin{tabular}{|l|} 
Cartagena \\
\end{tabular} & 3 & 0 & 0 & 0 & 0 & 0 & 7 & 0 & 0 & 40 & 0 & 2 & 10 & 0 & 0 & 501 & 8 & 7 & 0 & 0 & \\
\hline \begin{tabular}{|l|} 
Casanare \\
\end{tabular} & 0 & 0 & 0 & 1 & 0 & 0 & 3 & 0 & 0 & 13 & 0 & 0 & 3 & 0 & 0 & 35 & 2 & 0 & 1 & 1 & 0 \\
\hline Cauca & 15 & 0 & 2 & 0 & 0 & 0 & 15 & 0 & 0 & 53 & 1 & 0 & 6 & 0 & 0 & 66 & 3 & $\frac{1}{3}$ & 10 & 1 & \\
\hline Cesar & 4 & 0 & 0 & 0 & 0 & 0 & 45 & 0 & 2 & 87 & 1 & 0 & 19 & 0 & 0 & 118 & 3 & 3 & 17 & 3 & \\
\hline Choco & 4 & 1 & 0 & 1 & 0 & 0 & 2 & 0 & 0 & $\begin{array}{ll}13 \\
13\end{array}$ & 0 & 0 & 0 & 0 & 0 & 7 & $\frac{1}{3}$ & 0 & 2 & 1 & \\
\hline \begin{tabular}{|l|} 
Córdoba \\
\end{tabular} & 6 & 0 & 0 & 2 & 0 & 0 & 46 & 0 & 0 & 128 & 1 & 2 & 11 & 0 & 3 & 96 & 3 & 3 & 10 & 2 & \\
\hline \begin{tabular}{|l} 
Cundinamarca \\
\end{tabular} & 35 & 0 & 4 & 1 & 0 & 0 & 18 & 1 & 2 & 94 & 3 & 3 & 20 & 0 & 0 & 205 & 5 & 1 & 30 & 4 & \\
\hline \begin{tabular}{|l|} 
Guainía \\
\end{tabular} & 0 & 0 & 0 & 0 & 0 & 0 & 1 & 0 & 0 & 0 & 0 & 0 & 1 & 0 & 0 & 1 & 0 & 0 & 0 & 0 & 0 \\
\hline \begin{tabular}{|l} 
La Guajira \\
\end{tabular} & \begin{tabular}{c|}
4 \\
\end{tabular} & 0 & 0 & 0 & 0 & 0 & 17 & 1 & 0 & 54 & 1 & 0 & 0 & 0 & 0 & 16 & 3 & 0 & 3 & 2 & 0 \\
\hline \begin{tabular}{|l|} 
Guaviare \\
\end{tabular} & 0 & 0 & 0 & 1 & 0 & 0 & 1 & 0 & 0 & 10 & 0 & 2 & 0 & 0 & 0 & 3 & 0 & 0 & 2 & 1 & 0 \\
\hline Huila & 0 & 0 & 0 & 0 & 0 & 0 & 12 & 1 & 0 & $\begin{array}{l}67 \\
780 \\
\end{array}$ & 2 & 2 & 8 & 0 & 1 & 204 & 3 & 5 & 19 & 2 & 3 \\
\hline \begin{tabular}{|l} 
Magdalena \\
agla
\end{tabular} & 5 & 0 & 0 & 0 & 0 & 0 & 13 & 0 & 0 & \begin{tabular}{l|l}
78 \\
51
\end{tabular} & 1 & 1 & 5 & 0 & 0 & 26 & $\frac{0}{3}$ & $\frac{0}{0}$ & 10 & 2 & \\
\hline Meta & 44 & 0 & 1 & 1 & 0 & 0 & $\begin{array}{ll}30 \\
25\end{array}$ & 1 & 2 & \begin{tabular}{|l|l|}
51 \\
17
\end{tabular} & 1 & 0 & 7 & 0 & 0 & $\begin{aligned} 91 \\
244 \\
\end{aligned}$ & $\frac{3}{5}$ & 0 & 6 & 1 & \\
\hline \begin{tabular}{|l|} 
Nariño \\
\end{tabular} & 5 & 0 & 0 & $\frac{0}{3}$ & 0 & 0 & 25 & 0 & 1 & \begin{tabular}{l|l|l|l|l|}
127 & \\
81 &
\end{tabular} & $\frac{2}{5}$ & $\frac{2}{2}$ & $\begin{array}{r}9 \\
32\end{array}$ & 0 & $\frac{1}{3}$ & 244 & $\frac{5}{3}$ & $\frac{1}{2}$ & $\begin{array}{c}6 \\
1 \\
\end{array}$ & \begin{tabular}{c|c}
1 \\
0
\end{tabular} & \\
\hline \begin{tabular}{|l} 
Norte Santander \\
\end{tabular} & 3 & 0 & 0 & 3 & 0 & 0 & 29 & 0 & 0 & 81 & 5 & 2 & 33 & 0 & 3 & 71 & 3 & 2 & 1 & 0 & \\
\hline \begin{tabular}{|l} 
Putumayo \\
Oundion
\end{tabular} & 0 & 0 & 0 & 0 & 0 & 0 & \begin{tabular}{l|l}
12 \\
11
\end{tabular} & 0 & 0 & \begin{tabular}{l|l|}
27 \\
79
\end{tabular} & $\frac{0}{2}$ & $\frac{0}{1}$ & $\begin{array}{c}7 \\
18 \\
18\end{array}$ & $\frac{0}{0}$ & $\frac{0}{9}$ & $\begin{array}{r}56 \\
204 \\
\end{array}$ & $\frac{1}{6}$ & $\frac{2}{4}$ & \begin{tabular}{c|}
1 \\
18 \\
\end{tabular} & $\frac{1}{3}$ & \\
\hline \begin{tabular}{|l|} 
Quindio \\
Pisarald \\
\end{tabular} & 0 & 0 & 0 & 0 & 0 & 0 & 11 & & 0 & 79 & 2 & $\frac{1}{1}$ & 18 & 0 & $\frac{9}{0}$ & 204 & $\frac{6}{2}$ & $\frac{4}{5}$ & 18 & 3 & 1 \\
\hline \begin{tabular}{|l|l|l} 
Risaralda \\
$\sin$ Andrón
\end{tabular} & 6 & 0 & 0 & 1 & 0 & 0 & 23 & 0 & 1 & 104 & 1 & $\frac{1}{0}$ & 14 & 0 & 0 & 160 & 2 & 5 & $\frac{12}{8}$ & 3 & \\
\hline $\begin{array}{l}\text { San Andrés } \\
\text { Santa Marta }\end{array}$ & 0 & 0 & 0 & $\frac{0}{0}$ & 0 & 0 & \begin{tabular}{l|l}
1 \\
9
\end{tabular} & 0 & $\frac{0}{0}$ & 0 & 0 & 0 & 0 & $\frac{0}{3}$ & $\frac{0}{0}$ & $\frac{2}{42}$ & 0 & $\frac{0}{0}$ & 8 & 2 & 0 \\
\hline $\begin{array}{l}\text { Santa Marta } \\
\text { Santander }\end{array}$ & $\begin{array}{l}4 \\
8\end{array}$ & 0 & 0 & $\frac{0}{2}$ & $\begin{array}{ll}0 \\
0\end{array}$ & $\begin{array}{ll}0 \\
0\end{array}$ & \begin{tabular}{r|}
9 \\
19
\end{tabular} & \begin{tabular}{l|l}
0 \\
1
\end{tabular} & 0 & \begin{tabular}{l|l}
14 \\
59
\end{tabular} & $\frac{0}{2}$ & $\frac{0}{1}$ & $\frac{22}{14}$ & $\frac{3}{1}$ & $\frac{0}{0}$ & $\begin{array}{ll}42 \\
57\end{array}$ & $\frac{1}{2}$ & $\frac{0}{2}$ & $\frac{14}{14}$ & $\frac{2}{2}$ & $\frac{1}{0}$ \\
\hline Sucre & 2 & 0 & 1 & 0 & 0 & 0 & 14 & 0 & 1 & 64 & 1 & 1 & 2 & 0 & 0 & 55 & 1 & 1 & 23 & $\frac{2}{4}$ & \\
\hline Tolima & 2 & 1 & 0 & 0 & 0 & 0 & 13 & 0 & 0 & 58 & 2 & 0 & 5 & 0 & 0 & 73 & 4 & 0 & 19 & 2 & \\
\hline Valle & 21 & 0 & 0 & 5 & 0 & 0 & 55 & 2 & 1 & 282 & 4 & 22 & 20 & 0 & 0 & 681 & 9 & 7 & 94 & 13 & \\
\hline Vaupés & 0 & 0 & 0 & 0 & 0 & 0 & 0 & 0 & 0 & 1 & 0 & 0 & 0 & 0 & 0 & 1 & 0 & 0 & 0 & 0 & \\
\hline Vichada & 0 & 0 & 0 & 0 & 0 & 0 & \begin{tabular}{l|l}
1 \\
1
\end{tabular} & 0 & 0 & 1 & 0 & 0 & 0 & $x_{0}^{0}$ & 0 & 4 & $x_{0}^{0}$ & 0 & 0 & 0 & \\
\hline \begin{tabular}{|l} 
Total nacional \\
\end{tabular} & 220 & 2 & 9 & 48 & 1 & 0 & 675 & 27 & 16 & 2.729 & 57 & 60 & 568 & 13 & 21 & 6.171 & 156 & 102 & 643 & 97 & 65 \\
\hline
\end{tabular}

Tema central
Situación Nal.
Mortalidad
Trazadores
Brotes
Sarampión
Tablas




\begin{tabular}{|c|c|c|c|c|c|c|c|c|c|c|c|c|c|c|c|c|c|c|c|c|c|}
\hline \multirow[b]{2}{*}{ Departamento } & \multicolumn{3}{|c|}{ Morbilidad materna extrema } & \multicolumn{3}{|c|}{ Mortalidad perinatal y neonatal tardia } & \multicolumn{3}{|c|}{ Parálisisf flácida aguda } & \multicolumn{3}{|c|}{ Parotiditis } & \multicolumn{3}{|c|}{ Sindrome de rubeola congénita } & \multicolumn{3}{|c|}{ Tosferina } & \multicolumn{3}{|c|}{ Varicela } \\
\hline & 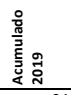 & $\begin{array}{l}\text { 을 } \\
\text { 恖 } \\
\end{array}$ & 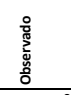 & 鄫 & $\begin{array}{l}\frac{8}{0} \\
\frac{0}{0} \\
\frac{5}{4} \\
\end{array}$ & 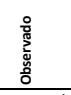 & 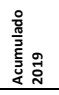 & 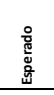 & 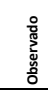 & 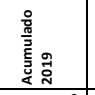 & $\begin{array}{l}\text { 윰 } \\
\text { 햅 } \\
\end{array}$ & 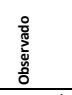 & 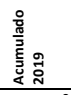 & 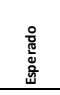 & 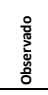 & 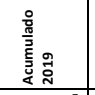 & 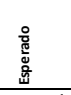 & 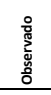 & 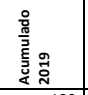 & $\begin{array}{l}\frac{0}{0} \\
\text { 咅 } \\
\end{array}$ & 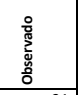 \\
\hline \begin{tabular}{|l|} 
Amazonas \\
Antioquiai
\end{tabular} & $\begin{array}{r}24 \\
1.336 \\
\end{array}$ & $\frac{2}{116}$ & 171 & $\frac{21}{804}$ & $\frac{3}{83}$ & & & & & \begin{tabular}{r|}
9 \\
1.363 \\
\end{tabular} & $\begin{array}{l}0 \\
65\end{array}$ & $\begin{array}{r}1 \\
133 \\
\end{array}$ & $\begin{array}{r}0 \\
47\end{array}$ & & & \begin{tabular}{r|}
500 \\
500
\end{tabular} & $\frac{1}{59}$ & & \begin{tabular}{|r|}
188 \\
5.049 \\
\end{tabular} & \begin{tabular}{|l|l|}
18 \\
884
\end{tabular} & $\begin{array}{r}21 \\
371 \\
\end{array}$ \\
\hline 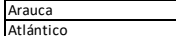 & $\frac{34}{429}$ & $\frac{7}{41}$ & $\frac{7}{73}$ & $\frac{40}{235}$ & $\frac{4}{25}$ & $\frac{7}{26}$ & & & & \begin{tabular}{r|r|r|r|}
115 \\
115
\end{tabular} & $\frac{2}{11}$ & $\begin{array}{c}6 \\
7\end{array}$ & $\frac{1}{0}$ & & & \begin{tabular}{l|l}
18 \\
10
\end{tabular} & $\frac{4}{2}$ & & $\begin{array}{r}4.15 \\
2.204 \\
\end{array}$ & \begin{tabular}{c|c}
60 \\
225 \\
\end{tabular} & $\frac{23}{280}$ \\
\hline Barranquilla & 514 & $\frac{41}{39}$ & 38 & 306 & 30 & & & & & 213 & $\frac{11}{13}$ & $\frac{1}{6}$ & 0 & & & 40 & $\frac{2}{1}$ & & 2.231 & 278 & 222 \\
\hline Bogotá & 4.277 & 354 & 465 & 884 & 103 & 86 & & & & 4.581 & 375 & 403 & 134 & & & 1.256 & 95 & & 9.706 & 3.081 & 817 \\
\hline $\begin{array}{l}\text { Bolivar } \\
\text { Boyacá }\end{array}$ & $\frac{538}{369}$ & $\frac{56}{33}$ & $\frac{73}{37}$ & $\frac{181}{132}$ & $\frac{22}{16}$ & $\frac{16}{12}$ & & & & $\begin{array}{l}65 \\
296 \\
\end{array}$ & $\frac{4}{29}$ & $\frac{3}{30}$ & & & & $\frac{47}{68}$ & $\frac{5}{7}$ & & $\begin{array}{l}1.436 \\
1.580\end{array}$ & $\frac{125}{228}$ & $\frac{110}{166}$ \\
\hline Buenaventura & 56 & 6 & 5 & 113 & 5 & 13 & & & & 2 & 0 & 0 & 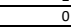 & & & 1 & 1 & & $\frac{1.00}{71}$ & 2 & $\frac{166}{6}$ \\
\hline Caldas & 176 & $\frac{12}{12}$ & 23 & 97 & 10 & 9 & & & & 117 & 10 & 7 & 1 & & & \begin{tabular}{l|l}
47 \\
\end{tabular} & 7 & & 627 & 226 & 57 \\
\hline$\frac{\mid \text { a aautetá }}{\text { Cartagena }}$ & $\frac{71}{688}$ & $\frac{12}{85}$ & $\frac{4}{85}$ & $\frac{66}{188}$ & $\frac{8}{27}$ & $\frac{6}{17}$ & & & & $\begin{array}{l}86 \\
74\end{array}$ & $\frac{4}{2}$ & $\frac{2}{4}$ & $\frac{1}{1}$ & & & $\begin{array}{l}78 \\
41\end{array}$ & $\frac{3}{5}$ & & 301 & 62 & $\frac{25}{103}$ \\
\hline $\begin{array}{l}\text { Cartagena } \\
\text { Casanare } \\
\end{array}$ & $\frac{688}{164}$ & $\frac{85}{11}$ & $\frac{85}{15}$ & $\frac{188}{51}$ & $\frac{27}{6}$ & $\frac{17}{8}$ & & & & $\frac{74}{32}$ & $\frac{2}{2}$ & $\frac{4}{1}$ & 1 & & & $\frac{41}{34}$ & $\frac{5}{3}$ & & $\frac{1.314}{621}$ & $\begin{aligned} 154 \\
45\end{aligned}$ & $\frac{103}{78}$ \\
\hline Cauca & $\frac{781}{781}$ & 55 & 73 & 204 & 25 & 23 & & & & 106 & 14 & 9 & 0 & & & 48 & 3 & & 612 & 116 & 71 \\
\hline $\begin{array}{l}\text { Char } \\
\text { Chocco }\end{array}$ & $\begin{array}{l}445 \\
195 \\
\end{array}$ & $\frac{36}{15}$ & $\frac{41}{14}$ & $\frac{241}{149}$ & $\frac{27}{15}$ & $\frac{17}{13}$ & & & & $\begin{array}{r}130 \\
54 \\
\end{array}$ & $\frac{10}{0}$ & $\frac{18}{0}$ & $\frac{1}{0}$ & & & $\begin{array}{l}70 \\
15\end{array}$ & 9 & & $\begin{array}{l}752 \\
101\end{array}$ & $\begin{array}{r}104 \\
5\end{array}$ & $\frac{75}{8}$ \\
\hline Córdoba & 419 & 60 & 30 & 362 & $\frac{13}{38}$ & 31 & & & & 423 & 3 & 26 & 0 & & & 10 & 4 & & 3.215 & 223 & \\
\hline \begin{tabular}{|l|} 
Cundinamarca \\
\end{tabular} & 1.305 & 93 & 125 & 344 & 37 & 32 & & & & 901 & 49 & 81 & 21 & & & 268 & 16 & & 3.368 & 701 & 281 \\
\hline La Guajira & 618 & $\frac{3}{62}$ & $\frac{0}{74}$ & $\frac{12}{358}$ & $\frac{1}{24}$ & $\frac{0}{30}$ & & & & \begin{tabular}{r|}
47 \\
47
\end{tabular} & $\frac{0}{2}$ & $\frac{0}{7}$ & $\frac{3}{2}$ & & & \begin{tabular}{r|r}
13 \\
\end{tabular} & & & $\begin{array}{r}43 \\
1.026 \\
\end{array}$ & \begin{tabular}{l|}
1 \\
57
\end{tabular} & $\frac{1}{103}$ \\
\hline Guaviare & 23 & 1 & 1 & 17 & 1 & 0 & 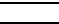 & & & 3 & 0 & 0 & 0 & & & 3 & 1 & & 151 & 10 & 37 \\
\hline Huila & 605 & 74 & 71 & 163 & 20 & 17 & & & & 692 & 19 & 85 & 0 & & & 87 & 9 & & 743 & 152 & 47 \\
\hline Magdalena & 316 & 33 & 38 & 156 & 17 & 14 & & & & 99 & 5 & 8 & 0 & & & 11 & 2 & & 1.038 & $71 \mid$ & 38 \\
\hline Meta & 196 & 30 & $\frac{18}{150}$ & 151 & 16 & 12 & 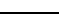 & & & 116 & 10 & $\frac{15}{75}$ & 5 & & & 33 & 4 & & & 1666 & 73 \\
\hline Nomite Santander & $\frac{226}{265}$ & 25 & 年3 & 230 & $\frac{23}{22}$ & $\frac{17}{27}$ & & & & $\begin{array}{l}355 \\
483\end{array}$ & $\frac{10}{24}$ & $\frac{75}{25}$ & $\frac{5}{0}$ & & & $\frac{174}{125}$ & $\frac{8}{13}$ & & $\begin{array}{l}1.1356 \\
1.949\end{array}$ & 234 & 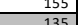 \\
\hline \begin{tabular}{|l|} 
Putumayo \\
\end{tabular} & 196 & $\frac{11}{11}$ & $\frac{14}{14}$ & 44 & 5 & 3 & & & & 288 & & & 4 & & & 15 & & & & & \\
\hline Quindio & 85 & 99 & 10 & 54 & 6 & 7 & 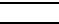 & & & \begin{tabular}{l|l}
66 & \\
\end{tabular} & 3 & 3 & 0 & & & 9 & 1 & & 652 & 96 & 65 \\
\hline Risaralda & 322 & 26 & 19 & 89 & 12 & 11 & & & & 103 & 7 & 9 & 0 & & & 32 & & & & 119 & 83 \\
\hline San Andrés & 5 & 1 & 0 & 10 & 2 & 0 & & & & 9 & 2 & 0 & 0 & & & 1 & 1 & & 193 & 15 & 30 \\
\hline 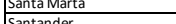 & 333 & 27 & 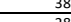 & 97 & 10 & 14 & & & & 12 & $\frac{2}{18}+2-1$ & $\frac{4}{11}$ & 0 & & & 5 & $\frac{3}{14},>>$ & & & (47 & 28 \\
\hline Sucture & 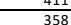 & $\begin{array}{l}30 \\
30\end{array}$ & 年 32 & 183 & $\frac{21}{20}$ & $\frac{10}{14}>>$ & & & & $\begin{array}{l}202 \\
116\end{array}$ & $\frac{18}{13}$ & $\frac{11}{6}$ & $\frac{0}{14}$ & & & $\frac{118}{123}$ & $\frac{14}{28}$ & & $\frac{1.6}{1.9}$ & $\begin{array}{l}384 \\
146 \\
\end{array}$ & 告18 \\
\hline olima & 373 & 35 & $\frac{21}{41}-24$ & 172 & 18 & 16 & & & & 1 & 13 & 9 & $\frac{6}{6}$ & & & 6 & & & & & 89 \\
\hline Valle & 1.394 & 88 & 172 & 402 & 51 & 34 & & & & 510 & 37 & 44 & 4 & & & 103 & 15 & & $\begin{array}{l}4.088 \\
\end{array}$ & 658 & 346 \\
\hline & 6 & 0 & & 13 & 1 & 2 & & & & 47 47 & 0 & 5 & & & & 43 & & & 27 & 5 & 1 \\
\hline Vichada & 34 & & 5 & 30 & 2 & 2 & & & & 10 & 1 & 0 & & & & 12 & 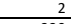 & & 72 & 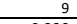 & \\
\hline Total nacional & 18.007 & 1.579 & 1.937 & 6.9999 & 762 & 647 & 11 & & & 11.925 [ & 762 & 1.067 & 259 & & & 3.503| & 339 & & 52.480 & 9.230 & 3 \\
\hline
\end{tabular}

\begin{tabular}{l} 
Tema central \\
Situación Nal. \\
\hline Mortalidad \\
\hline Trazadores \\
\hline Brotes \\
\hline Sarampión \\
\hline Tablas
\end{tabular}



de 2019

\section{Comportamiento de la notificación por departamento a semana 40}

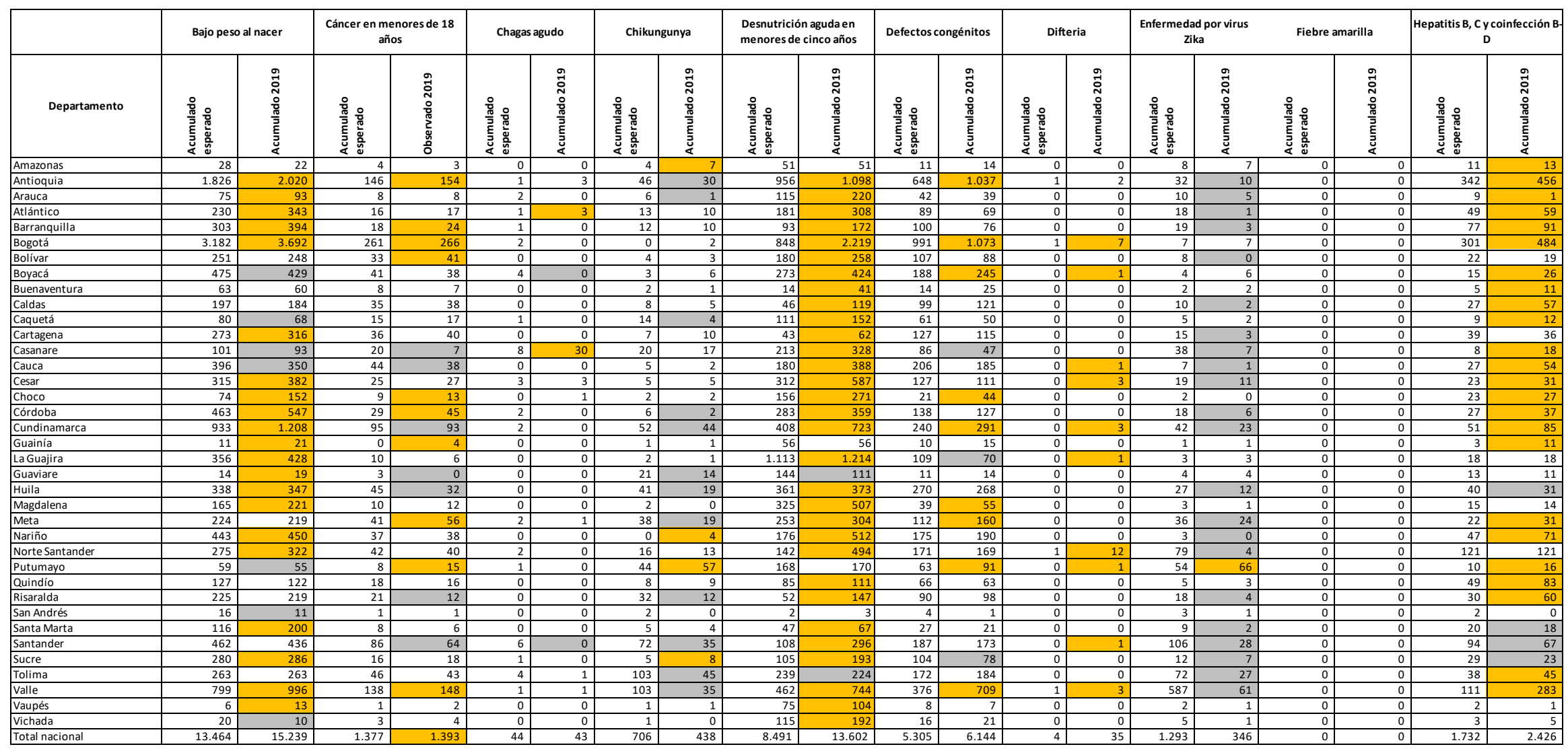

Tema central

Situación Nal.

Mortalidad

Trazadores

Brotes

Sarampión

Tablas 


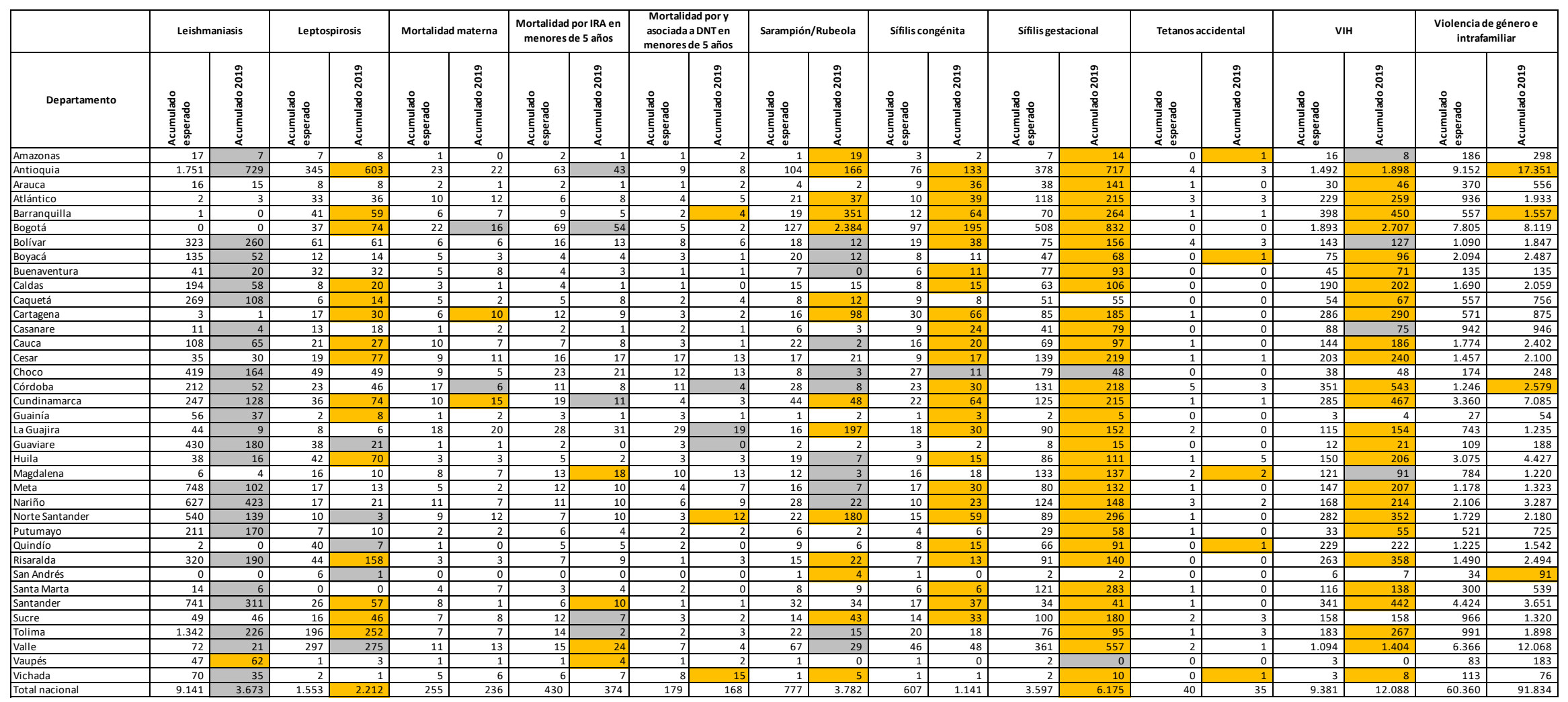

Tema central

Situación Nal.

Mortalidad

Trazadores

Brotes

Sarampión

Tablas 


\section{Semana epidemiológica 40}

29 de sept. al 5 de octubre de 2019

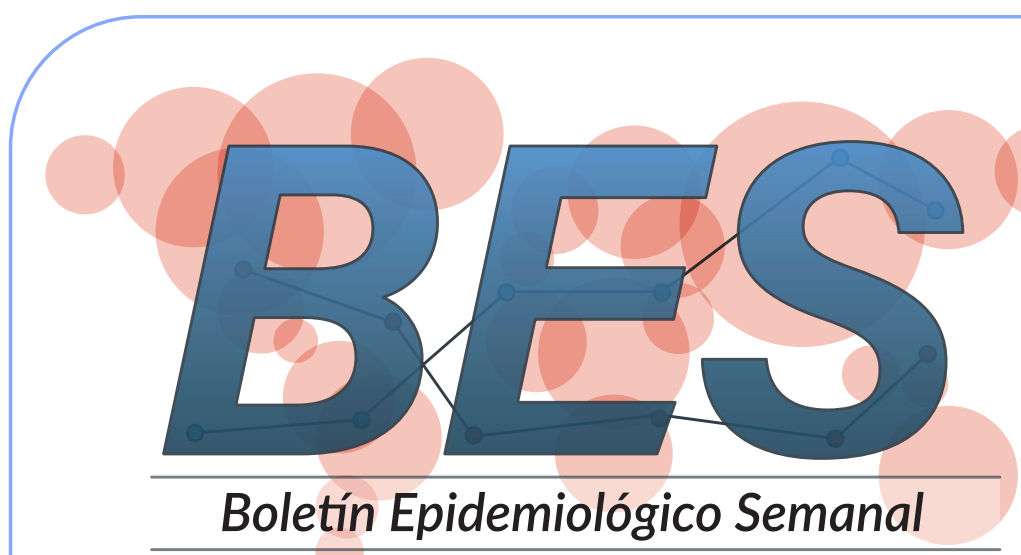

\section{Boletín Epidemiológico Semanal}

Expertos Temáticos Dra. Martha Lucia Ospina Martínez

Dr. Franklyn Edwin Prieto Alvarado

Dra. Diana Walteros

Subdirectora de Prevención Vigilancia y Control en Salud Públic

Una publicación del.

Instituto Nacional de Salud Dirección de Vigilancia y Análisis del Riesgo en Salud Pública Publicación en línea: ISSN 2357-6189 https://doi.org/10.33610/23576189.2019.40

Asistencia técnica de:
Situación Nacional

Grupo Sivigila sivigila@ins.gov.co

\section{Mortalidad}

Jessika Manrique Sanchez jmanrique@ins.gov.co

Grace Alejandra Avila gavilam@ins.gov.co

Eventos Trazadores

Andrea Jineth Rodriguez Reyes arodriguezr@ins.gov.co

Brotes

Gestor sistema de alerta temprana eri@ins.gov.co

Jorge Díazjdiaz@ins.gov.co

Tablas de mando

Verónica Tangarife vtangarife@ins.gov.co

Diana Rivera drivera@ins.gov.co

Edición

Hernán Quijada Bonilla hquijada@ins.gov.co

Diseño y diagramación

Alexander Casas acasasc@ins.gov.co

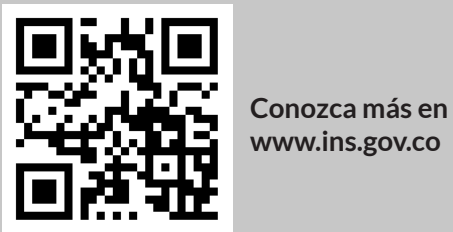

aris

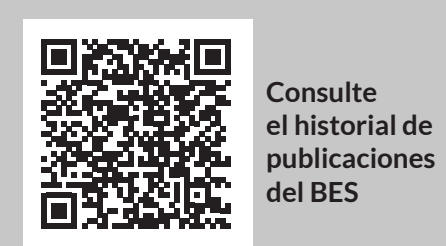

La salud

es de todos

Minsalud 